\title{
Density functional theory calculations of self- and Xe diffusion in U3Si2
}

Middleburgh, Simon; Andersson, David ; Stanek, Chris; Claisse, Antoine; Beeler, Ben; Liu, X-Y

\section{Journal of Nuclear Materials}

DOI:

10.1016/j.jnucmat.2018.12.021

Published: 01/03/2019

Peer reviewed version

Cyswllt i'r cyhoeddiad / Link to publication

Dyfyniad o'r fersiwn a gyhoeddwyd / Citation for published version (APA):

Middleburgh, S., Andersson, D., Stanek, C., Claisse, A., Beeler, B., \& Liu, X-Y. (2019). Density functional theory calculations of self- and Xe diffusion in U3Si2. Journal of Nuclear Materials, 515, 312-325. https://doi.org/10.1016/j.jnucmat.2018.12.021

\section{Hawliau Cyffredinol / General rights}

Copyright and moral rights for the publications made accessible in the public portal are retained by the authors and/or other copyright owners and it is a condition of accessing publications that users recognise and abide by the legal requirements associated with these rights.

- Users may download and print one copy of any publication from the public portal for the purpose of private study or research.

- You may not further distribute the material or use it for any profit-making activity or commercial gain

- You may freely distribute the URL identifying the publication in the public portal ?

Take down policy

If you believe that this document breaches copyright please contact us providing details, and we will remove access to the work immediately and investigate your claim. 


\title{
Density functional theory calculations of self- and Xe diffusion in $\mathrm{U}_{3} \mathrm{Si}_{2}$
}

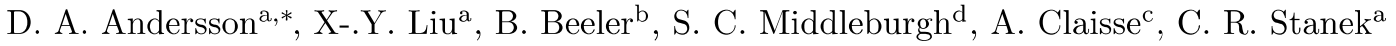 \\ ${ }^{a}$ Materials Science and Technology Division, Los Alamos National Laboratory P.O. Box 1663, Los Alamos, NM 87545, USA \\ ${ }^{b}$ Fuel Modeling and Simulation, Idaho National Laboratory, P.O. Box 1625, Idaho Falls, ID 83415, USA \\ ${ }^{c}$ Westinghouse Electric Sweden AB, SE-721 63, Västerås, Sweden \\ ${ }^{d}$ Nuclear Futures Institute, Bangor University, Bangor LL57 2DG, UK
}

\begin{abstract}
Uranium silicide, $\mathrm{U}_{3} \mathrm{Si}_{2}$, has been proposed as an advanced nuclear fuel to be used in light water reactors (LWRs). Development of this alternative to the predominant current fuel, $\mathrm{UO}_{2}$, is motivated by enhanced accident tolerance as a result of higher thermal conductivity as well as improved fuel cycle economics through increased uranium density. In order to accurately model the fuel performance of $\mathrm{U}_{3} \mathrm{Si}_{2}$, the diffusion rate of point defects, which is related to self-diffusion, and of fission gas atoms must be determined. DFT calculations are used to predict the $\mathrm{U}$ and $\mathrm{Si}$ point defect concentrations, the corresponding self-diffusivities, the preferred Xe trap site and the Xe diffusivity. Effects of irradiation are not considered. A low defect formation energy and a high entropy for Si interstitials give rise to Si-rich non-stoichiometry at elevated temperatures. Both U and Si self-diffusion and Xe diffusion are anisotropic as a consequence of the tetragonal crystal structure of $\mathrm{U}_{3} \mathrm{Si}_{2}$. Si diffusion occurs by interstitial mechanisms in both the $a-b$ plane and along the $c$ axis, while the $\mathrm{U} c$ axis diffusion rate is controlled by a vacancy mechanism. Interstitial diffusion of $\mathrm{U}$ is very fast in the $a-b$ plane of the $\mathrm{U}_{3} \mathrm{Si}_{2}$ crystal structure. Xe atoms prefer to occupy $\mathrm{U}$ vacancy trap sites. The highest Xe diffusion rate occurs by a vacancy mechanism in both the $a-b$ plane and along the $c$ axis. The diffusion rate is similar in the $a-b$ plane and along the $c$ axis. U and Si self-diffusion and Xe diffusion are all faster in $\mathrm{U}_{3} \mathrm{Si}_{2}$ than intrinsic $\mathrm{U}$ and Xe diffusion in conventional $\mathrm{UO}_{2}$ nuclear fuel.
\end{abstract}

\section{Introduction}

Uranium dioxide, $\mathrm{UO}_{2}$, has been used as fuel in light water reactors (LWRs) since the early days of the technology and over the years it has been optimized to provide reliable operational performance and safety. New advanced fuels continue to be considered for use in LWRs in order to further improve the fuel performance, economics and safety. The accident at the Fukushima-Daiichi power station following the earthquake and tsunami in Japan in 2011 put renewed emphasis on increasing the accident tolerance of LWR fuels and, even though the main concern in this incident was the loss of coolant and the $\mathrm{Zr}$ cladding reacting with water to form hydrogen, the fuel element is an integral part of

*Corresponding author. Present address: Materials Science and Technology Division, Los Alamos National Laboratory, MS G755, Los Alamos, NM 87545, USA, Tel: +1 505 6658621

Email address: andersson@lanl.gov (D. A. Andersson) any accident tolerant fuel concept [1]. For example, $\mathrm{U}_{3} \mathrm{Si}_{2}$ has been proposed as an alternative to $\mathrm{UO}_{2}$ fuel because it offers improved thermal conductivity, which results in lower centerline temperatures, and higher $U$ density. The latter is beneficial from operational and economical standpoints, but could also offset changes to the cladding material that give rise to higher neutron losses compared to the current Zr-based cladding, such as iron-chromiumaluminum ( $\mathrm{FeCrAl}$ ) alloys [2] and $\mathrm{Cr}$-coated $\mathrm{Zr}$ alloys [3] with increased oxidation resistance at high temperature.

In order to license a new commercial nuclear fuel, it is necessary to be able to predict the fuel behavior during operation, which requires knowledge of material properties as function of, for example, temperature, pressure, initial fuel micro-structure and irradiation history, or more precisely the changes in micro-structure due to irradiation [4]. Experimental testing of $\mathrm{U}_{3} \mathrm{Si}_{2}$ at conditions relevant to LWRs is limited, however some data exist on U- 
Si compounds for research reactors, which operate at much lower temperatures than LWRs [5]. Out-of-pile experimental data has been reported for thermo-physical properties such as thermal and electronic conductivity, specific heat, oxidation reactions and phase stability [6-17]. The first results of irradiation testing for LWR conditions will soon become available. However, little is known about either point defect diffusion, self-diffusion or fission gas diffusion, neither under intrinsic nor irradiation conditions. These properties govern swelling of the fuel and fission gas release, which are two of the most important fuel performance behaviors in $\mathrm{U}_{3} \mathrm{Si}_{2}$ [18].

In order to begin to address these gaps in understanding, we have used density function theory (DFT) calculations applying the Hubbard $U$ model for the U $5 f$ electrons to investigate thermal diffusion (no effects of irradiation) of U, Si and Xe atoms by vacancy and interstitial mechanisms. This entails studying point defect thermodynamics and kinetics as well as Xe interactions with point defects. Diffusivities are predicted and analyzed in relation to diffusion of point defects and fission gas atoms in $\mathrm{UO}_{2}$.

\section{Theory and methodology}

\subsection{Density functional theory calculations of defect energies and entropies}

The DFT calculations were performed with the Vienna Ab Initio Simulation (VASP) package [1923] applying the GGA-PBE exchange correlation potential with Hubbard $U$ (onsite Coulomb parameter) and $J$ (onsite exchange parameter) terms included for the $\mathrm{U} 5 f$ orbitals in order to capture the effects of strong correlations [24-26], which follows established methodology for $\mathrm{U}_{3} \mathrm{Si}_{2}[9,17,27$ 31]. The rotationally invariant implementation of $\mathrm{DFT}+U$ due to Dudarev et al. [26] was applied. In this method, only the difference $U-J$ enters the formulation. An effective $U-J$ parameter of 1.5 $\mathrm{eV}$ was chosen in Ref. [27] to balance the competing effects of ensuring thermodynamic stability and matching the experimental volume for the $\mathrm{U}_{3} \mathrm{Si}_{2}$ phase with space group $P 4 / \mathrm{mbm}$. This choice was also adopted in our study.

The main benefit of the GGA $+U$ compared to the standard GGA approach is that spurious new phases at the USi and $\mathrm{U}_{3} \mathrm{Si}_{2}$ stoichiometries, which lack experimental confirmation, are avoided and that the $\mathrm{U}_{3} \mathrm{Si}_{2}$ phase is mechanically stable with no imaginary phonon frequencies [27]. On the list of drawbacks or deficiencies of the GGA $+U$ method, the volume of $\mathrm{U}_{3} \mathrm{Si}_{2}$ is slightly overestimated and the ferromagnetic ground state obtained from $\mathrm{DFT}+U$ deviates from the paramagnetic behavior seen in experiments $[27,32]$. The application of a ferro-magnetic ordering in $\mathrm{U}_{3} \mathrm{Si}_{2}$ is only expected to have a minor impact on point defect and diffusion properties, because the difference in energy between different magnetic structures is much smaller than typical point defect formation and migration energies (see Sec. 3). The disordered magnetic moments in the paramagnetic phase of $\mathrm{U}_{3} \mathrm{Si}_{2}$ can be modeled with a special quasi-random structure (SQS) [33]. Although the SQS method was not applied in the present study, the small difference between the ferromagnetic and anti-ferromagnetic configurations (0.02 eV/atom) indicates that a paramagnetic structure could be competitive. In comparison, the non-magnetic solution is almost a factor of 10 higher in energy. It is important to note that any attempt to calculate thermodynamic and diffusion properties of point defects in $\mathrm{U}_{3} \mathrm{Si}_{2}$ with the standard GGA approach would fail, since the lattice is unstable and would relax into a distorted structure with lower energy than the $\mathrm{U}_{3} \mathrm{Si}_{2}$ phase of interest.

The thermodynamic and kinetic properties of vacancies, interstitials, $U$ anti-sites and $\mathrm{Xe}$ atoms were investigated by supercell calculations. Defect energies and migration barriers were calculated in a $2 \times 2 \times 3$ supercell (120 atoms) expansion of the $\mathrm{U}_{3} \mathrm{Si}_{2}$ unit cell (see Fig 1). In Refs. [9, 18] a $2 \times 2 \times 2$ cell was used to study defect formation energies, however, in this supercell vacancy migration in the $c$ direction would not be separated by any stationary atom and, consequently, we have opted to expand the supercell in the $c$ direction to three repeating units. redIn order to assess the impact of expanding to a $2 \times 2 \times 3$ supercell we have also calculated a few barriers and defect energies using the smaller $2 \times 2 \times 2$ supercell. The migration barrier for a $\mathrm{U}(2 \mathrm{a})$ vacancy is reduced from $1.71 \mathrm{eV}\left(E_{m}^{a a}\right.$, see Sec. 2.3) and $1.21 \mathrm{eV}\left(E_{m}^{c c}\right.$, see Sec. 2.3) for the $2 \times 2 \times 3$ cell to $1.53 \mathrm{eV}\left(E_{m}^{a a}\right)$ and $1.01 \mathrm{eV}\left(E_{m}^{c c}\right)$ for the $2 \times 2 \times 2$ cell, which implies that both barriers are impacted by the choice of supercell. The defect energies are affected a little less than the barriers, but still by a similar order of magnitude, about 0.15 $\mathrm{eV}$ for the $\mathrm{U}$ (2a, see Sec. 2.2) vacancy. The difference between the $2 \times 2 \times 3$ supercell and even larger 
cells is expected to be smaller than going from the $2 \times 2 \times 2$ to the $2 \times 2 \times 3$ supercell.

Integration over the Brillouin zone of the $2 \times 2 \times 3$ supercell was performed on $2 \times 2 \times 2$ MonkhorstPack k-point meshes. The plane-wave cut-off energy was set to $500 \mathrm{eV}$ and the partial occupancies were smeared according to the Methfessel-Paxton method with a smearing width of $0.1 \mathrm{eV}$. The atomic positions, supercell volume and supercell shape were allowed to fully relax (zero pressure on the cell and zero forces on the ions) in the energy minimization calculations. The convergence criteria for force relaxation was $0.01 \mathrm{eV} / \AA$. Migration barriers were calculated using the climbing image nudged elastic band (NEB) method [34] with five images. The NEB calculations were performed with the volume fixed at that of the starting configuration. redThe diffusion mechanisms were identified by enumerating viable pathways, performing NEB calculations and then refining the pathways for cases where alternative options emerge. This approach is subject to the limitations of our ability to identify all important options and there is always a chance that a mechanism was missed. As such, the predicted diffusion coefficients represent an upper bound. However, if a critical step in the diffusion mechanism was omitted, that could lead to an overestimation of the barrier. Obviously, we have tried hard to avoid both of these sources of error. A way of circumventing this limitation would be to apply molecular dynamics or accelerated molecular dynamics simulations to identify the most relevant diffusion pathways in an unbiased way, but that exercise is beyond reach in our study and also requires a reliable empirical potential. The current U-Si empirical potential [35] has not yet been extensively tested for kinetic properties.

Vibrational defect entropies were calculated from the normal mode phonon frequencies following the approach of Mishin et al. [36]. At temperatures higher than the Debye temperature, the entropy of crystalline solids can be approximated as:

$$
S=-k_{B} \sum_{n=1}^{3 N-3} \ln \left(\frac{h \nu_{n}}{k_{B} T}\right)+(3 N-3) k_{B},
$$

where $N$ is the number of atoms in the crystal, $k_{B}$ is the Boltzmann constant, $T$ is the temperature, and $\nu_{n}$ is the normal vibrational frequency of the crystal. There are three modes that are zero for every supercell, corresponding to translational modes, which are neglected. In the harmonic ap- proximation, the normal mode vibrational frequencies are calculated by diagonalizing the dynamical force matrix of the system at constant volume. The dynamical matrix was obtained via the finite displacement [56] method using the PHONOPY software [37] and VASP for the force calculations. Due to the high cost of calculating the dynamical matrix from DFT, we used the smaller $2 \times 2 \times 2$ or $1 \times 2 \times 3$ supercell of $\mathrm{U}_{3} \mathrm{Si}_{2}$ for the defect formation and binding entropies. The same methodology was previously used to calculate the phonon spectra in bulk $\mathrm{U}_{3} \mathrm{Si}_{2}$ [27]. The use of an empirical potential, such as the recently developed U-Si MEAM potential [35], could be an alternative to DFT calculations for phonon properties of defects. redAt high temperatures, anharmonic effects contribute to the defect formation entropies and energies. This contribution can be included through the quasiharmonic approximation, which calculates energies and phonons at several different volumes to account for the effect of thermal expansion. Due to the computational expense of performing such calculations based on DFT for the many different defect configurations under investigation here, this was not attempted in the present study. The neglect of anharmonicity in our calculations could affect the accuracy of the results at high temperatures.

The dynamical matrices were calculated at constant volume and the resulting entropies were then adjusted to account for the defect formation or binding volume by adding $\Delta V\left(\frac{d S}{d V}\right)_{\mathrm{U}_{3} \mathrm{Si}_{2}}$, where $\Delta V$ is the defect or binding volume and $\left(\frac{d S}{d V}\right)_{\mathrm{U}_{3} \mathrm{Si}_{2}}$ is the volume dependence of the entropy for $\mathrm{U}_{3} \mathrm{Si}_{2}$ without any defects. Both $\Delta V$ and $\left(\frac{d S}{d V}\right)_{\mathrm{U}_{3} \mathrm{Si}_{2}}$ were obtained from DFT calculations.

For accurate calculation of the dynamical matrices it is important to minimize even small changes in total energy and forces due to meta-stable solutions that may occur for $f$ electron systems within the $\mathrm{DFT}+U$ methodology. Even though this issue is small for $\mathrm{U}_{3} \mathrm{Si}_{2}$ compared to $\mathrm{UO}_{2}$, it was addressed by making sure that the forces acting on atoms in the perturbed structures used to calculate the dynamical matrix are consistent with the wave function for the ground-state structure of $\mathrm{U}_{3} \mathrm{Si}_{2}$. In the finite displacement method this is enforced by starting the electronic minimization of the perturbed structures with the ground-state wave function as an initial guess. All phonon calculations applied symmetry relations to reduce the number of independent displacements. For accurate phonon 
calculations, the forces were converged to typically on the order of $10^{-4} \mathrm{eV} / \AA$ for the ground-state defect structures.

The attempt frequency for migration $\left(\nu_{A_{B}}=\right.$ $\nu_{A_{B}, 0} \exp \left(\frac{S_{m}}{k_{B} T}\right)$, see Sec. 2.3) can be calculated from the normal frequencies at the saddle point and at the initial configuration of the defect [38]. However, due to the high computational cost of calculating phonons based on the $2 \times 2 \times 3$ supercell generally needed for migration properties, attempt frequencies were only calculated directly from DFT for a subset of cases that can be approximated by smaller supercells, e.g. the $2 \times 2 \times 2$ or $1 \times 2 \times 3$ supercell. Other attempt frequencies were estimated from the range of values obtained for this subset. This simplification is deemed necessary and we do not believe that it significantly impacts any of our conclusions.

The energies and entropies of $\mathrm{U}_{5} \mathrm{Si}_{4}$ and $\mathrm{U}_{3} \mathrm{Si}$, the neighboring phases, are required to establish references (the partial energies and entropies, or chemical potentials, of $\mathrm{U}$ and $\mathrm{Si}$ ) for calculating defect formation energies and entropies in $\mathrm{U}_{3} \mathrm{Si}_{2}$. The DFT calculations for these compounds used the same plane-wave cut-off energy as for $\mathrm{U}_{3} \mathrm{Si}_{2}$ and the $\mathrm{k}$-point meshes were chosen to give at least the same accuracy. Other computational details were the same as for $\mathrm{U}_{3} \mathrm{Si}_{2}$.

\subsection{Point defect model for $\mathrm{U}_{3} \mathrm{Si}_{2}$}

Diffusion of U, Si and Xe atoms is enabled by point defects. In order to predict self-diffusion of $\mathrm{U}$ and $\mathrm{Si}$ and diffusion of $\mathrm{Xe}$ in $\mathrm{U}_{3} \mathrm{Si}_{2}$ the concentration of vacancy and interstitial point defects must be calculated. The $\mathrm{U}_{3} \mathrm{Si}_{2}$ crystal structure is tetragonal and it has two unique $\mathrm{U}$ sites, $\mathrm{U} 2 \mathrm{a}(0,0,0)$ and $\mathrm{U} 4 \mathrm{~h}(0.181,0.681,0.5)$, and one Si site, $4 \mathrm{~g}(0.611$, $0.111,0)$, see Fig. 1. The two uranium sites will be distinguished by their crystallographic notation. For interstitials the most stable configuration of U and $\mathrm{Si}$ atoms, as reported in Ref. [9], are considered (see Fig. 3).

Following Boltzmann statistics in the dilute limit, point defect concentrations (per $\mathrm{U}_{3} \mathrm{Si}_{2}$ unit cell) are expressed as

$$
c_{A_{B}}=z_{A_{B}} \exp \left(-\frac{F_{A_{B}, f}}{k_{B} T}\right)
$$

where $A$ denotes the defect type (vacancy, interstitial or anti-site) and $B$ the species involved ( $U$ or $\mathrm{Si}), z_{A_{B}}$ is the site multiplicity, $T$ is the temperature

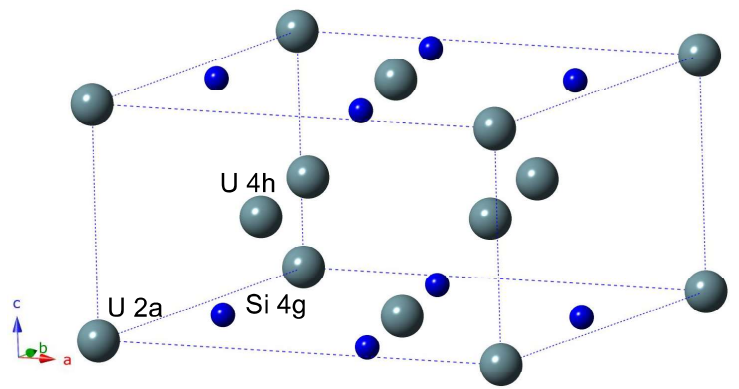

Figure 1: The tetragonal unit cell of $\mathrm{U}_{3} \mathrm{Si}_{2}(a=b \neq c$, space group $P 4 / \mathrm{mbm})$ with the U $2 \mathrm{a}(0,0,0)$, U $4 \mathrm{~h}(0.181,0.681,0.5)$ and $\mathrm{Si} 4 \mathrm{~g}(0.611,0.111,0)$ atoms highlighted.

and $k_{B}$ the Boltzmann constant. The corresponding site fractions $\left(y_{A_{B}}\right)$ and the fraction of $A_{B}$ with respect to the total amount of $B\left(u_{A_{B}}\right)$ can be derived from $c_{A_{B}}$. The free energy $(F)$ is calculated from the energy $(E)$ and entropy $(S)$ according to $F=E-T S$. The defect formation energy for vacancies and interstitials is obtained from supercell calculations according to:

$$
E_{A_{B}, f}=E\left(A_{B}, N \pm 1\right) \mp e_{B}-E(N)
$$

and the entropy as

$$
S_{A_{B}, f}=S\left(A_{B}, N \pm 1\right) \mp s_{B}-S(N) .
$$

$E\left(A_{B}, N \pm 1\right)$ is the energy of a $\mathrm{U}_{3} \mathrm{Si}_{2}$ supercell that contains one defect of type $A_{B}, N$ is the number of atoms without the defect and $N \pm 1$ is the number with the defect (interstitial $=$ plus and vacancy $=$ minus, for consistency with the interstitial notation), $e_{B}$ is the partial energy of $\mathrm{U}$ or $\mathrm{Si}$ detailed below (interstitial $=$ minus and vacancy $=$ plus, for consistency with the interstitial notation). $S\left(A_{B}, N \pm 1\right)$ and $s_{B}$ are the corresponding entropies. For U anti-sites Eqs. 3 and 4 are slightly modified to include both the $\mathrm{U}$ and $\mathrm{Si}$ partial quantities with the number of atoms kept at the same number as the perfect cell $(N)$ :

$$
E_{\mathrm{U}_{\mathrm{Si}}, f}=E\left(\mathrm{U}_{\mathrm{Si}}, N\right)+e_{\mathrm{Si}}-e_{\mathrm{U}}-E(N)
$$

and

$$
S_{\mathrm{U}_{\mathrm{Si}}, f}=S\left(\mathrm{U}_{\mathrm{Si}}, N\right)+s_{\mathrm{Si}}-s_{\mathrm{U}}-S(N) .
$$

$\mathrm{U}$ anti-site defects are included because they have been shown to be important for non-stoichiometry in the U-rich part of the phase diagram [9]. The concentration of $\mathrm{Si}$ anti-site defects was calculated 
to be less significant [9] and it is consequently not included in the present study. Since $\mathrm{U}_{3} \mathrm{Si}_{2}$ is metallic, it is not necessary to take the charge state of the defect into consideration.

Three different cases for the partial molar quantities (chemical potentials) are considered; 1) the environment is Si-rich and $\mathrm{U}_{3} \mathrm{Si}_{2}$ is in equilibrium with USi (or $\mathrm{U}_{5} \mathrm{Si}_{4}$ ); 2) the environment is Urich and $\mathrm{U}_{3} \mathrm{Si}_{2}$ is in equilibrium with $\mathrm{U}_{3} \mathrm{Si}$ (at high temperature the equilibrium is with uranium metal) and 3) $\mathrm{U}_{3} \mathrm{Si}_{2}$ is near "perfect" stoichiometry. The stoichiometric or nearly stoichiometric case is bound by the chemical potentials of the Si and Urich cases. As will be shown in Sec. 3.1, the "perfect" stoichiometric case is not attained in $\mathrm{U}_{3} \mathrm{Si}_{2}$ and this case is better characterized as an intermediate between the Si and U-rich conditions. Nevertheless, the notation "stoichiometric (stoich.)" or nearly stoichiometric will be used. We approximate the chemical potentials for the stoichiometric case by assuming equilibrium between USi (or $\mathrm{U}_{5} \mathrm{Si}_{4}$ ) and $\mathrm{U}_{3} \mathrm{Si}$. The $\mathrm{U}_{5} \mathrm{Si}_{4}$ phase is not included in the experimentally assessed phase diagram [11], which rather lists USi (FeB structure) as the next stable Si-rich phase after $\mathrm{U}_{3} \mathrm{Si}_{2}$. However, it has been identified in one experiment [39] and also suspected in the discussion of the assessed phase diagram [11], even though it was left out of the published version of the phase diagram. Moreover, the $\mathrm{U}_{5} \mathrm{Si}_{4}$ phase was predicted to be stable or very close to stability by DFT calculations [9]. Since $\mathrm{DFT}+U$ predicts the $\mathrm{FeB}$ phase of USi to have imaginary phonons (note that the experimental FeB structure is believed to be stabilized by oxygen impurities [40]), we will rather use the $\mathrm{U}_{5} \mathrm{Si}_{4}$ phase as reference. A very recent study found USi to be dynamically unstable, while $\mathrm{U}_{5} \mathrm{Si}_{4}$ was predicted to have imaginary phonon modes [31]. The reason for this discrepancy with our results is not immediately clear to us. Multiple tests were performed for the $\mathrm{U}_{5} \mathrm{Si}_{4}$ phonons and all our simulations predicted the frequencies to be positive. The partial energy and entropy are calculated by solving the following equations:

$$
\begin{aligned}
& E\left(\mathrm{U}_{a} \mathrm{Si}_{b}\right)=a e_{\mathrm{U}}+b e_{\mathrm{Si}} \\
& E\left(\mathrm{U}_{c} \mathrm{Si}_{d}\right)=c e_{\mathrm{U}}+d e_{\mathrm{Si}},
\end{aligned}
$$

and

$$
\begin{aligned}
& \tilde{S}\left(\mathrm{U}_{a} \mathrm{Si}_{b}\right)=a s_{\mathrm{U}}+b s_{\mathrm{Si}} \\
& \tilde{S}\left(\mathrm{U}_{c} \mathrm{Si}_{d}\right)=c s_{\mathrm{U}}+d s_{\mathrm{Si}} .
\end{aligned}
$$

$E\left(\mathrm{U}_{a} \mathrm{Si}_{b}\right)$ and $E\left(\mathrm{U}_{c} \mathrm{Si}_{d}\right)$ are the energies of the $\mathrm{U}_{a} \mathrm{Si}_{b}$ and $\mathrm{U}_{c} \mathrm{Si}_{d}$ phases defining the equilibrium conditions. $\tilde{S}\left(\mathrm{U}_{a} \mathrm{Si}_{b}\right)=\frac{N}{N-1} S\left(\mathrm{U}_{a} \mathrm{Si}_{b}\right)$ and $\tilde{S}\left(\mathrm{U}_{c} \mathrm{Si}_{d}\right)=\frac{N}{N-1} S\left(\mathrm{U}_{c} \mathrm{Si}_{d}\right)$ are the corresponding entropies and $N$ is the number of atoms in the cells used to describe $\mathrm{U}_{a} \mathrm{Si}_{b}$ and $\mathrm{U}_{c} \mathrm{Si}_{d}$, respectively. The $\frac{N}{N-1}$ scaling factor is a consequence of Eq. 1 summing over the $3(N-1)$ non-zero phonon modes, rather than the modes corresponding to the total number of atoms, $3 N$. The acoustic modes in the long wave-length limit, analogous to translation, are excluded from the summation. This formulation follows the methodology in Ref. [36]. For large $N$ the scaling factor approaches 1 and in our case it is $\approx 1.01$, which is still a small correction. The model predictions of point defect concentrations and the resulting non-stoichiometry are presented in Sec. 3.1.

\subsection{Self-diffusion in $U_{3} S i_{2}$}

Although treated as a scalar in isotropic materials, diffusivity is strictly a tensor property. For the tetragonal crystal structure of $\mathrm{U}_{3} \mathrm{Si}_{2}$ only the diagonal elements are non-zero. They satisfy $D^{a a}=$ $D^{b b} \neq D^{c c}$, where the superscript denotes the tensor component (superscripts are used to distinguish tensor components instead of the more common subscript notation, because subscripts indicate the defect type in our notation). This results in a unique self-diffusion behavior of $\mathrm{U}$ and $\mathrm{Si}$ in the $a-b$ plane and along the $c$ axis, respectively. Each component of the diffusion tensor (labeled $R$ ) is obtained as the sum over the corresponding diffusivity for all defects and paths enabling diffusion of species $B$ in the direction defined by the tensor component, with each term controlled by the concentration and mobility of the point defect [41]:

$$
D_{B}^{R}=\sum_{A_{B}} u_{A_{B}} D_{A_{B}, 0}^{R} \exp \left(-\frac{E_{A_{B}, m}^{R}}{k_{B} T}\right)
$$

In this equation, $u_{A_{B}}$ is the fraction of $A_{B}$ point defects with respect the total amount of atom $B$ obtained from Eq. 2, $E_{A_{B}, m}^{R}$ is the effective migration barrier for diffusion of $B$ involving vacancies or interstitials (labeled $A$, where $A_{B}$ indicates the defect involving an atom of type $B$ ) and $D_{A_{B}, 0}^{R}$ is the pre-exponential factor for the diffusion mechanism. 
The latter is given by

$$
D_{A_{B}, 0}^{R}=\frac{1}{D_{z}} f Z_{A_{B}}^{R}\left(d_{A_{B}}^{R}\right)^{2} \nu_{A_{B}, 0}^{R} \exp \left(\frac{S_{A_{B}, m}^{R}}{k_{B}}\right),
$$

where $d_{A_{B}}^{R}$ is the jump distance in the direction defined by the tensor component and $Z_{A_{B}}^{R}$ is the number of (equivalent) neighboring sites that the atom can jump to for a particular mechanism, $\nu_{A_{B}, 0}^{R}$ is the characteristic vibrational frequency, $S_{A_{B}, m}^{R}$ is the migration entropy and $f$ is the correlation factor (here approximated as 1). The factor $\frac{1}{D_{z}}$ is equal to $\frac{1}{2}$ for mechanisms that take place in one dimensional (along the $c$ axis) and $\frac{1}{4}$ for mechanisms in the $a$ - $b$-plane (two dimensions). $\quad \nu_{A_{B}, 0}^{R}$ and the exponential of $S_{A_{B}, m}^{R}$ together define the attempt frequency $\left(\nu_{m}^{R}\right)$. The prediction of self-diffusion coefficients is detailed in Sec. 3.2.

\subsection{Xe diffusion in $U_{3} S i_{2}$}

$\mathrm{Xe}$ atoms either occupy interstitial $\left(X e_{i}\right)$ or vacancy (substitutional, $\mathrm{Xe}_{\mathrm{U} 2 \mathrm{a}}, \mathrm{Xe}_{\mathrm{U} 4 \mathrm{~h}}$ and $\mathrm{Xe}_{\mathrm{Si}}$ ) trap sites in $\mathrm{U}_{3} \mathrm{Si}_{2}$. Although the trap site may consist of multiple vacancies, we restrict our study to single vacancies with the possibility of a second vacancy binding to enable diffusion. Effects of further clustering is left as future work. Diffusion occurs by either an interstitial Xe atom jumping to a nearest neighbor interstitial site or by a vacancy mechanism for Xe atoms occupying substitutional trap sites. The details of the diffusion mechanisms are presented in Sec. 3.4. In short, the interstitial mechanisms involve moving from one interstitial site to a neighboring empty site of the same type. The migration pathway may involve traversing through a second type of interstitial site. Diffusion of substitutional Xe involves interacting with a $\mathrm{U}$ or Si vacancy, quantified by the vacancy binding energy, and then migrating either as a bound cluster through one or several steps or through a single Xe jump and then detaching the assisting vacancy. The vacancy mechanisms are distinguished by the mobile cluster, for example, denoted as $\mathrm{Xe}_{\mathrm{U} 2 \mathrm{aU}} \mathrm{a}$ for a Xe atom occupying $U$ 2a trap site and with another $U 2$ a vacancy assisting diffusion. The vacancy mechanisms follow the same recipe as for $\mathrm{Xe}$ and other fission products in $\mathrm{UO}_{2}$, see for example Refs. [42-46] for additional details, and UN [47].

The Xe diffusivity for each component of the tensor (denoted by a superscript $R=a a, b b$ or $c c$, similar to self-diffusion) is determined by the sum over the corresponding diffusivity for each individual trap site (denoted by $\mathrm{Xe}_{X}$ ) in the direction dictated by the tensor component, weighted by the fraction of Xe atoms occupying that site,

$$
\begin{array}{r}
D_{\mathrm{Xe}}^{R}=\sum_{X} y_{\mathrm{Xe}_{X}, \mathrm{Xe}_{\mathrm{e}}} y_{\mathrm{Va}} m_{\mathrm{Xe}_{X}, \mathrm{Va}} \\
\exp \left(-\frac{F_{\mathrm{Xe}_{X}, b}}{k_{B} T}\right) D_{\mathrm{Xe}_{X}, 0}^{R} \exp \left(-\frac{E_{\mathrm{Xe}_{X}, m}^{R}}{k_{B} T}\right) .
\end{array}
$$

For each tensor component $R, E_{\mathrm{Xe}_{X}, m}^{R}$ is the effective migration barrier for diffusion of $\mathrm{Xe}$ involving trap site $\mathrm{Xe}_{X}, D_{\mathrm{Xe}_{X}, 0}^{R}$ is the pre-exponential factor for the mechanism, $y_{\mathrm{Xe}_{X}, \mathrm{Xe}}$ is the relative concentration of $\mathrm{Xe}$ in trap site $X, y_{\mathrm{Va}}$ is the equilibrium site fraction of vacancies on the sublattice involved in the diffusion mechanism derived from Eq. 2, $F_{\mathrm{Xe}_{X}, b}$ is the $(1 \mathrm{NN})$ binding free energy of vacancies to the trap site $\left(F_{\mathrm{Xe}_{X}, b}=E_{\mathrm{Xe}_{X}, b}-T S_{\mathrm{Xe}_{X}, b}\right.$, where $E_{\mathrm{Xe}_{X}, b}$ and $S_{\mathrm{Xe}_{X}, b}$ are the corresponding energy and entropy, respectively) and $m_{\mathrm{Xe}_{X} \text {, Va }}$ is the the number of equivalent sites that the vacancy can bind to. The latter three factors represent the fraction of Xe trap sites with a bound vacancy enabling diffusion. The equilibrium fraction of vacancies on the interstitial sublattices is approximated to be 1 (low concentration of interstitials). The preexponential factor $D_{\mathrm{Xe}_{\mathrm{X}}, 0}^{R}$ is calculated similarly to Eq. 12. For migration mechanisms involving multiple steps, $D_{\mathrm{Xe}_{X}, 0}^{R}$ and $E_{\mathrm{Xe}_{X}, m}^{R}$ are calculated from the highest saddle point along the pathway. Diffusion may occur by different types of vacancies, $V_{\mathrm{U} 2 \mathrm{a}}, V_{\mathrm{U} 4 \mathrm{~h}}$ or $V_{\mathrm{Si}}$, all of which are treated as separate mechanisms.

The formulation above covers mechanisms where the assisting vacancy and the trap site move as a bound unit as well as where the assisting vacancy detaches from the cluster to complete the diffusion step. The rate-limiting step for the latter case would be the sum of the barrier for bulk migration of the assisting vacancy and the binding energy. This assumes that the intra-cluster step for $\mathrm{Xe}$ is a low barrier event, which is typically the case. For very strong binding energies, the cluster diffusion rate is controlled by the migration properties of the cluster and the expression in Eq. 13 is no longer valid. This corresponds to $y_{\mathrm{Va}} m_{\mathrm{Xe}_{X}, V a} \exp \left(-\frac{F_{\mathrm{Xe}_{X}, b}}{k_{B} T}\right) \geq 1$, which implies that the trap site with a bound vacancy strongly dominates over the trap site itself (and the current model breaks down). For this case the diffusion 
rate is given by the migration rate of the cluster itself. The Xe $\mathrm{U}_{2 \mathrm{aSi}}$ cluster exceeds this limit close to the melting point, but not in the temperature range studied in this paper $(T \leq 1500 \mathrm{~K})$. However, this limitation should be kept in mind as the diffusion models derived here are applied outside this temperature range.

The relative concentration of Xe in a particular trap site $\left(y_{\mathrm{Xe}_{X}, \mathrm{Xe}}\right)$ is obtained from the solution energy,

$$
F_{\mathrm{Xe}_{X}, s}=F_{\mathrm{Xe}_{X}, f}+F_{\mathrm{Xe}_{X}, i},
$$

where $F_{\mathrm{Xe}_{X}, f}$ is the formation free energy of trap site $\mathrm{Xe}_{X}$, which for vacancies is given by the energies and entropies in Eqs. 3 and 4. For interstitials it is equal to zero. The incorporation energy $F_{\mathrm{Xe}_{X}, i}$ is the energy associated with placing a Xe atom into the trap site. An isolated $\mathrm{Xe}$ atom is taken as the reference for $\mathrm{Xe}$. The solution energy gives the equilibrium concentration of $\mathrm{Xe}$ in the $\mathrm{U}_{3} \mathrm{Si}_{2}$ lattice. The fractional occupation, $y_{\mathrm{Xe}_{X}, \mathrm{Xe}}$, is calculated according to Boltzmann statistics,

$$
y_{\mathrm{X}_{X}, \mathrm{Xe}}=\frac{z_{\mathrm{Xe}_{X}} \exp \left(-\frac{F_{\mathrm{Xe}_{X}, s}}{k_{B} T}\right)}{\sum_{X} z_{\mathrm{Xe}_{X}} \exp \left(-\frac{F_{\mathrm{Xe}_{X}, s}}{k_{B} T}\right)} .
$$

$z_{\mathrm{Xe}_{X}}$ is the trap site multiplicity. The predicted Xe trap site concentrations and diffusion rates are presented in Secs. 3.3 and 3.4, respectively.

\subsection{Effective diffusivities in polycrystalline mate- rials}

Secs. 2.3 and 2.4 define the tensor for selfdiffusion and Xe diffusion in single crystals. A nuclear fuel pellet is polycrystalline and the effective diffusivity is a function of the grain micro-structure. Simple bounds for the polycrystalline diffusivity are defined by [48]

$$
\begin{aligned}
3\left(\frac{1}{D^{a a}}+\right. & \left.\frac{1}{D^{b b}}+\frac{1}{D^{c c}}\right)^{-1} \leq D^{e f f} \\
& \leq \frac{1}{3}\left(D^{a a}+D^{b b}+D^{c c}\right)
\end{aligned}
$$

These bounds will be used to estimate the range of diffusivities that can be observed in $\mathrm{U}_{3} \mathrm{Si}_{2} \mathrm{nu}$ clear fuels. redThe polycrystalline bounds should be used with some care, since they neglect any contribution from grain boundary diffusion, which could be important for small grain sizes, but not for typical fuel microstructures with grain sizes of at least several microns, and are not appropriate for intra-granular phenomena, such as the first stage of fission gas release.

\section{Results}

\subsection{Point defect concentrations in $U_{3} S i_{2}$}

The calculated point defect energies and entropies for the nearly stoichiometric, Si-rich and U-rich thermodynamic limits defined in Sec. 2.2 are collected in Table A.1 of the appendix and the point defect concentrations are plotted as function of temperature in Figs. 2 (stoichiometric) and A.1 (Si-rich and U-rich conditions, see appendix). The table also includes the defect volumes $(\Delta V$, the difference in volume between the defect supercell and the corresponding bulk $\mathrm{U}_{3} \mathrm{Si}_{2}$ cell) used to calculate the entropies. The resulting non-stoichiometry $(x$ in $\left.\mathrm{U}_{3} \mathrm{Si}_{2+x}\right)$ is also shown in the figures. Si intersti-

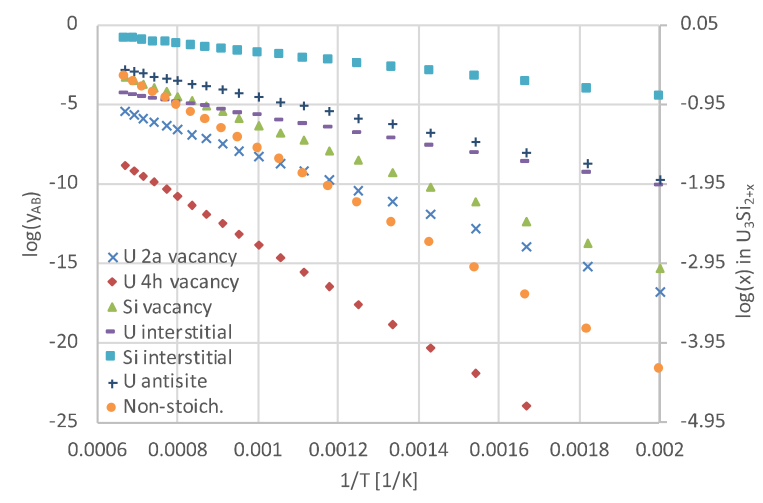

Figure 2: Equilibrium defect concentrations (plotted as site fractions, $y_{A_{B}}$, left-hand axis) and non-stoichiometry in $\mathrm{U}_{3} \mathrm{Si}_{2+x}$ ( $x$, right-hand $\mathrm{y}$-axis) for nearly stoichiometric $\mathrm{U}_{3} \mathrm{Si}_{2}$. Si-rich and U-rich conditions are shown in Fig. A.1 of the appendix.

tials dominate in all thermodynamic limits, which leads to hyper-stoichiometry with respect to Si for all three cases, not only for Si-rich conditions. The hyper-stoichiometry is accentuated at high temperature, while at low temperature the composition is close to stoichiometric. This implies that the thermodynamic case labeled as stoichiometric is in fact non-stoichiometric and further away from the $\mathrm{U}_{3} \mathrm{Si}_{2}$ composition than for U-rich conditions. Note that we are still keeping the stoichiometric designation for this case. After Si interstitials, U anti-sites and $\mathrm{U}$ interstitials follow as the species with second and third highest concentration. The $\mathrm{U} 2 \mathrm{a}$ vacancy has a lower formation energy than the $U$ th vacancy. Both exhibit a lower concentration than Si vacancies, except for Si-rich conditions when U $2 \mathrm{a}$ and $\mathrm{Si}$ vacancies are of similar magnitude. The Si vacancy concentration goes up sharply with increasing temperature and for some conditions it overtakes the 
U interstitial concentration. For U-rich conditions at high temperature, the $\mathrm{U}$ anti-site concentration becomes significant and starts to drive the nonstoichiometry back towards $x=0$ and eventually $x$ takes negative values, though this occurs above the temperatures shown in Fig. A.1 $(T>1500 \mathrm{~K})$, close to the melting temperature of $\mathrm{U}_{3} \mathrm{Si}_{2}$.

Compared to Ref. [9], which studied $\mathrm{U}_{3} \mathrm{Si}_{2}$ nonstoichiometry based on defect energies alone, the inclusion of entropies further emphasizes the $\mathrm{U}_{3} \mathrm{Si}_{2}$ non-stoichiometry induced by $\mathrm{Si}$ interstitials at high temperature and, to lesser extent, U anti-site defects. Since the Si interstitial and U anti-site concentrations in this range are much higher than what would be consistent with the assumption of dilute concentrations of point defects in Eq. 2, the numbers should be interpreted as a qualitative prediction of the formation of a non-stoichiometric Sirich $\mathrm{U}_{3} \mathrm{Si}_{2+x}$ phase rather than a precise measure of the value of $x$. Future work should consider more advanced modeling approaches that include defect-defect interactions, such as cluster expansion techniques $[33,49,50]$, to describe the nonstoichiometry. New experimental phase diagram data would also be valuable for validation in this temperature regime. Although experimental data is rather scarce, existing phase diagrams portray the $\mathrm{U}_{3} \mathrm{Si}_{2}$ phase as a stoichiometric compound up to the melting point [11], which is not consistent with our prediction.

\subsection{Self-diffusion in $U_{3} S i_{2}$}

The self-diffusion mechanisms by vacancies and interstitials are illustrated in Figs. 3 (interstitials) and 4 (vacancies). The migration barriers $\left(E_{A, m}^{R}\right)$ and pre-exponential factors $\left(D_{A_{B}, 0}^{R}\right.$, given by Eq. 12) describing the mobilities are summarized in Table A.2 (see appendix). The attempt frequencies $\left(\nu_{m}^{R}\right)$, the jump distance $\left(d_{A_{B}}^{R}\right)$ and the number of (equivalent) neighboring sites $\left(Z_{A_{B}}^{R}\right)$ defining $D_{A_{B}, 0}^{R}$ are collected in Table A.3 of the appendix. The mobilities combined with the point defect concentrations derived in Sec. 3.1 enable calculation of the rate of self-diffusion according to Eq. 11. The resulting activation energies (the temperature dependent factor of Eq. 11 denoted $\left.E_{A, a}^{R}\right)$ and preexponential factors (the temperature independent factor of Eq. 11 denoted $\left.D_{A_{B}, a}^{R}\right)$ for self-diffusion are listed in Table A.2 (see appendix) and plotted in Fig. 5. The polycrystalline bounds defined by Eq. 16 are also shown in this figure and the Ar- rhenius relations for the polycrystalline bounds are listed in Table 1.

\begin{tabular}{lccc}
\hline \hline & $\mathrm{U}$ & $\mathrm{Si}$ & $\mathrm{Xe}$ \\
\hline$E_{A, a}^{\text {high }}$ & 1.18 & 2.35 & 2.96 \\
$E_{A, a}^{\text {low }}$ & 2.89 & 3.46 & 2.91 \\
$D_{A, a}^{\text {high }}$ & $6.22 \cdot 10^{-7}$ & $1.60 \cdot 10^{-5}$ & $8.29 \cdot 10^{-5}$ \\
$D_{A, a}^{\text {low }}$ & $1.00 \cdot 10^{-5}$ & $7.68 \cdot 10^{-5}$ & $5.62 \cdot 10^{-5}$ \\
\hline \hline
\end{tabular}

Table 1: The activation energy $\left(E_{A, a}^{\text {high }}, E_{A, a}^{\text {low }}\right.$, units in eV) and pre-exponential factor $\left(D_{A, a}^{\text {high }}, D_{A, a}^{\text {low }}\right.$, units in $\left.\mathrm{m}^{2} / \mathrm{s}\right)$ of the high and low bounds for self-diffusion of $\mathrm{U}\left(D_{\mathrm{U}}^{e f f}\right.$, units in $\left.\mathrm{m}^{2} / \mathrm{s}\right)$ and $\mathrm{Si}\left(D_{\mathrm{Si}}^{e f f}\right.$, units in $\left.\mathrm{m}^{2} / \mathrm{s}\right)$ and diffusion of $\mathrm{Xe}$ $\left(D_{\mathrm{Xe}}^{\text {eff }}\right.$, units in $\mathrm{m}^{2} / \mathrm{s}$ ) in nearly stoichiometric $\mathrm{U}_{3} \mathrm{Si}_{2}$.

The lowest barriers are obtained for $\mathrm{U}$ interstitials and $U$ th vacancies in the $a-b$ plane. However, the $\mathrm{U}$ 4h vacancy barrier (step 1 in Fig 4a) is not the rate-limiting step for diffusion since it involves traversing through a $U$ 2a vacancy, which is a more stable configuration and thus has a higher barrier (step 2 in Fig 4a). The low barrier for U 4 h vacancies consequently does not translate to rapid diffusion. The fastest self-diffusion rate for both $\mathrm{U}$ and $\mathrm{Si}$ atoms refers to interstitials in the $a-b$ plane. Below, the U and Si vacancy and interstitial mechanisms are discussed in more detail.

The U interstitial forms a split or dumbbell structure and migrates by moving one of the split atoms into a regular site, while the other kicks out a neighboring atom to form a new split structure one lattice site away (see Fig. 3a and b). The migration barrier in the $a-b$ plane for the split $\mathrm{U}$ interstitial is low and diffusion by this mechanism is faster than any of the vacancy mechanisms. Si interstitials in the $a-b$ plane move much slower than U interstitials, but still constitutes the most rapid mechanism for Si diffusion. The pathway starts in an interstitial site between two U 2 a atoms and traverses through a second interstitial site between two $\mathrm{Si}$ atoms before completing the step by migrating to a neighboring interstitial site of the same type as the starting point (see Fig. 3c). The high self-diffusion rate of Si interstitials is in part a consequence of the high concentration of this point defect (see Figs. 2 and A.1 of the appendix). Interstitial diffusion along the $c$ axis exhibits high barriers for both $\mathrm{U}$ and $\mathrm{Si}$ atoms. The Si mechanism for diffusion along the $c$ axis also involves a component in the $a-b$ plane (see Fig. 3d), but this component is much slower than the mechanism in the $a-b$ plane only, referred 

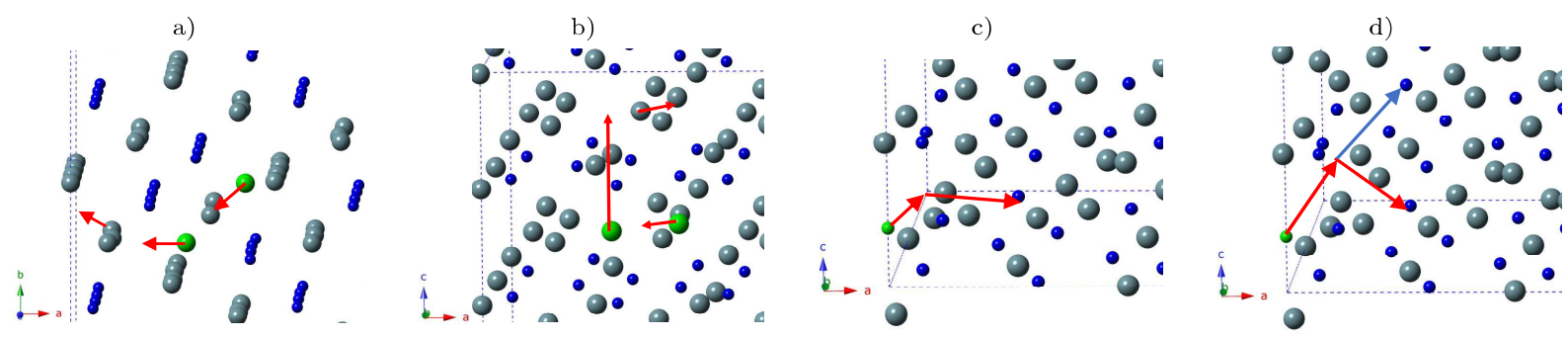

Figure 3: Interstitial diffusion mechanisms in $\mathrm{U}_{3} \mathrm{Si}_{2}$. Interstitials are highlighted in green, a) and b) illustrate U interstitials and c) and d) Si interstitials. The dotted lines indicate the boundary of the $2 \times 2 \times 3$ computational supercell. For clarity the plots are zoomed in on the mechanism of interest. a) $\mathrm{U}$ interstitial diffusion in the $a-b$ plane (red arrows). The U interstitial forms a split structure involving one of the $\mathrm{U} 4 \mathrm{~h}$ uranium atoms. b) The diffusion mechanism along the $c$ axis involves moving one of the split interstitials in the $c$ axis and the other split atom back into a regular site, while a new split structure is formed by kicking out the $\mathrm{U} 4 \mathrm{~h}$ atom in the same plane as the migrating interstitial is moving to. c) Si interstitial diffusion in the $a-b$ plane. The Si interstitial occupies a position in between two U 2a atoms (labeled aa only in Fig. 5b). d) Si interstitial diffusion in the $a-b$ plane (second mechanism) and along the $c$ axis. The two mechanisms are very similar, with only the direction of the second jump from intermediate interstitial site being different.

a)

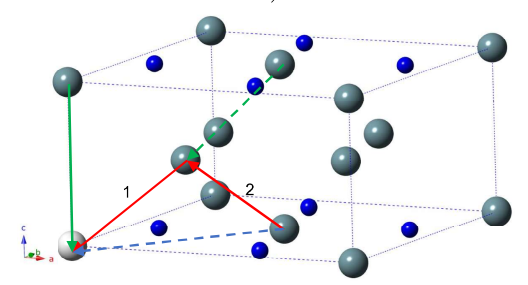

b)

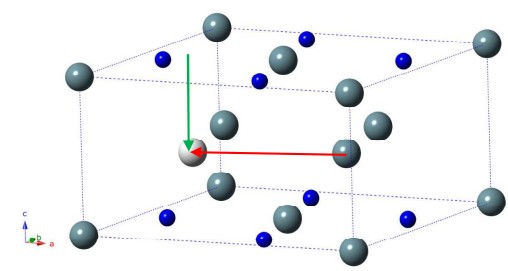

c)

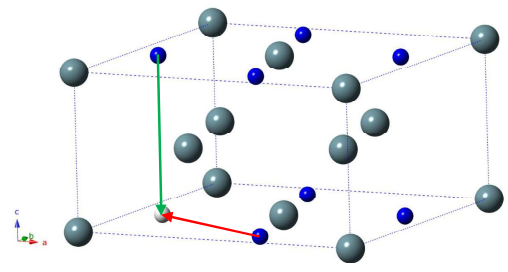

Figure 4: Vacancy diffusion mechanisms in $\mathrm{U}_{3} \mathrm{Si}_{2}$. Vacancies are highlighted in white contrast. The dotted lines indicate the boundary of the $\mathrm{U}_{3} \mathrm{Si}_{2}$ unit cell. a) $\mathrm{U} 2 \mathrm{a}$ vacancy diffusion in the $a-b$ plane (red arrows) and along the $c$ axis (green arrow). The fastest $a-b$ plane mechanism involves several steps (labeled 1 and 2) and traverses through a U $4 \mathrm{~h}$ site. The $a-b$ plane mechanism may also have $c$ component, as indicated by the dashed green arrow. Direct migration of a $\mathrm{U} 2 \mathrm{a}$ vacancy is much slower (blue dashed line). b) U $4 \mathrm{~h}$ vacancy diffusion in the $a-b$ plane (red arrow) and along the $c$ axis (green arrow). There is also a $U$ th mechanism identical to the multi-step mechanism in a) but starting with a $U$ 4 h vacancy (not shown). c) Si vacancy diffusion in the $a-b$ plane (red arrow) and along the $c$ axis (green arrow).

to above.

For $\mathrm{U}$ vacancies, migration along the $c$ axis is faster than the in-plane $a-b$ mechanisms. U 4 h vacancies have a higher barrier than $\mathrm{U} 2 \mathrm{a}$ vacancies along the $c$ direction. The fastest migration mechanism for $\mathrm{U}$ vacancies within the $a-b$ plane involves both $\mathrm{U} 2 \mathrm{a}$ and $\mathrm{U} 4 \mathrm{~h}$ vacancies. The mechanism is illustrated for a $U$ 2a vacancy in Fig. $4 a$ and the same mechanism can also move $U$ 4 h vacancies between sites. It is just a matter of which site is defined as the starting position, the effective diffusion rate is the same when both the defect formation energies and migration barriers have been taken into account. The direct migration mechanisms between two $\mathrm{U} 2 \mathrm{a}$ and two $\mathrm{U} 4 \mathrm{~h}$ vacancies (see Figs. 4a and b), respectively, have much higher barriers than the mechanism that involves a vacancy traversing both sites. There is also a slight variation of the $a-b$ plane mechanism that results in migration along the $a-b$ plane and along the $c$ axis, see Fig. 4a. The $c$ component of this step is slower than direct migration along the $c$ axis. The migration barriers for Si vacancies in the $a-b$ plane and along the $c$ axis (see Fig. 4c) are very close to each other. Both barriers are higher than for $U$ vacancies.

Diffusion of $U$ anti-site defects is not included in Fig. 5, because the rate is expected to be negligible based on the concentration of anti-sites and the slow diffusion of Si vacancies, which is assumed to be the rate limiting step for the diffusion of $U$ atoms on the Si sublattice.

\subsection{Xe solution energies, entropies and preferred trap site}

The Xe incorporation and solution energies and entropies are summarized in Table A.4 of the appendix for the nearly stoichiometric, Si-rich and 
a)

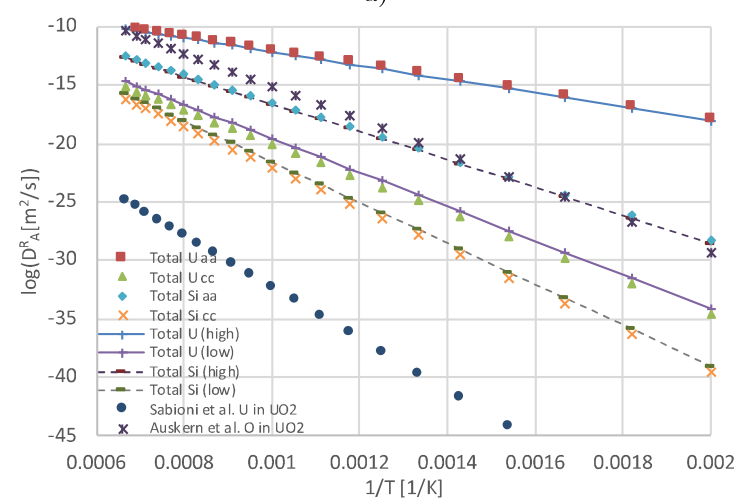

b)

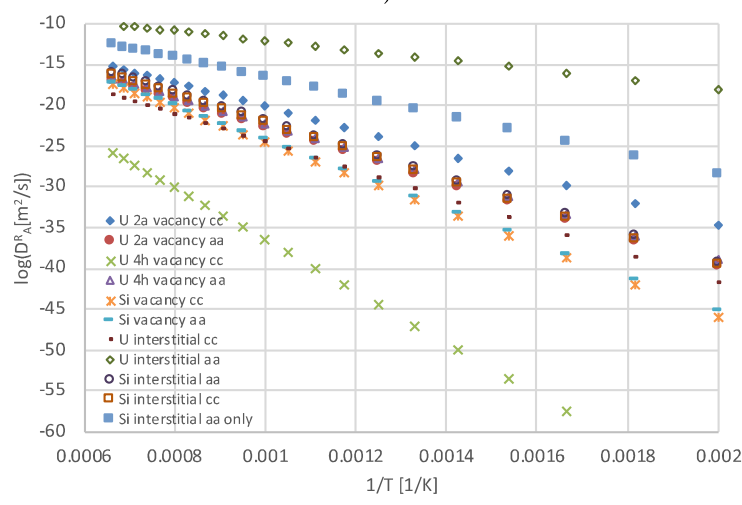

Figure 5: a) The $D_{A}^{a a}=D_{A}^{b b}$ and $D_{A}^{c c}(A=\mathrm{U}$ or $\mathrm{Si})$ tensor components for self-diffusion of $\mathrm{U}$ and $\mathrm{Si}$ in nearly stoichiometric $\mathrm{U}_{3} \mathrm{Si}_{2}$. The high and low bounds show the range of possible values in polycrystalline samples. The predictions for $\mathrm{U}_{3} \mathrm{Si}_{2}$ are compared to the experimental data for selfdiffusion of $\mathrm{U}$ [51] and $\mathrm{O}$ in $\mathrm{UO}_{2}$ [52]. b) Diffusivity tensor components of individual self-diffusion mechanisms in $\mathrm{U}_{3} \mathrm{Si}_{2}$ for the same conditions as in a). Self-diffusion under $\mathrm{Si}$ and U-rich conditions are shown in Fig. A.2 of the appendix.

U-rich thermodynamic limits. This table also includes the defect volumes used to calculate the entropies. Fig. 6 plots the relative trap site occupations for nearly stoichiometric $\mathrm{U}_{3} \mathrm{Si}_{2}$ and Fig. A.3 of the appendix plots the same information for the U-rich and Si-rich thermodynamic conditions. The trap site formation energies and entropies needed to complete Eq. 14 are listed in Table A.1. The thermodynamic solubility of $\mathrm{Xe}$ in $\mathrm{U}_{3} \mathrm{Si}_{2}$ is negligable and remains below approximately $10^{-14}$ even at temperatures close to the experimental melting point. The $\mathrm{U} 2 \mathrm{a}$ vacancy $\left(\mathrm{Xe}_{\mathrm{U} 2 \mathrm{a}}\right.$ ) is predicted to be the preferred trap site for all conditions and it is followed by the interstitial $\left(\mathrm{Xe}_{I}\right)$ and $\mathrm{Si}$ vacancy $\left(\mathrm{Xe}_{\mathrm{Si}}\right)$ positions. The interstitial site is higher in energy but more favored from an entropic perspec-

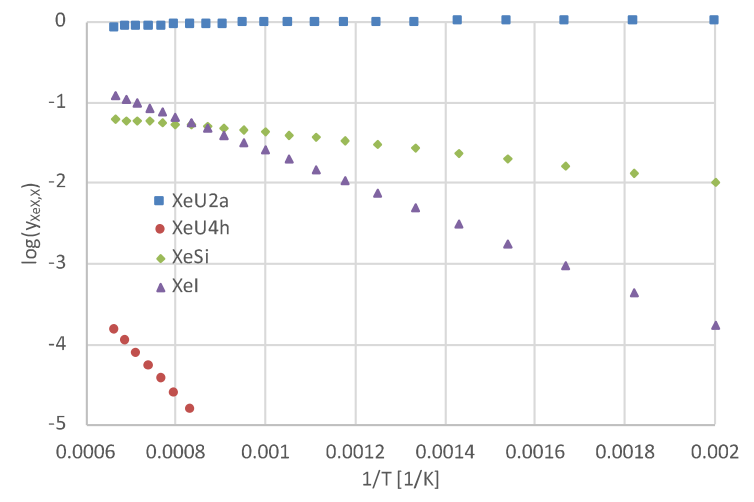

Figure 6: Fractional occupation of Xe trap sites as function of temperature for nearly stoichiometric $\mathrm{U}_{3} \mathrm{Si}_{2}$, defined by Eq. 15. The results for $\mathrm{Si}$ and U-rich conditions are shown in A.3 of the appendix.

tive. The lowest energy interstitial position forms a split interstitial or dumbbell structure with a $\mathrm{U}$ $4 \mathrm{~h}$ atom.

\subsection{Xe diffusion in $U_{3} S i_{2}$}

The interstitial and vacancy migration mechanisms for Xe are illustrated in Figs. A.4, A.5 and A.6 of the appendix. The vacancy mechanisms involve binding a vacancy to the Xe substitutional trap sites. The binding energies and entropies of vacancies to Xe trap sites $\left(E_{\mathrm{Xe}_{X}, b}^{R}\right.$ and $\left.S_{\mathrm{Xe}_{X}, b}^{R}\right)$ are collected in Table A.5 (see appendix), which also contain the defect volumes used to calculate the binding entropies. Migration barriers $\left(E_{\mathrm{Xe}_{X}, m}^{R}\right)$ and pre-exponential factors $\left(D_{\mathrm{Xe}_{X}, 0}^{R}\right)$ for diffusion are reported in Table A.6 of the appendix. The attempt frequencies $\left(\nu_{A_{B}}^{R}=\nu_{A_{B}, 0}^{R} \exp \left(S_{A_{B}, m}^{R} / k_{B}\right)\right)$, the jump distance $\left(d_{A_{B}}^{R}\right)$ and the number of (equivalent) neighboring sites $\left(Z_{A_{B}}^{R}\right)$ defining $D_{\mathrm{Xe}_{X}, 0}^{R}$ are collected in Table A.3 (see appendix). In most cases the bound cluster diffuses as a unit by a mechanism involving multiple steps, but there are a few cases where it is more efficient to separate the Xe-vacancy cluster after intra-cluster migration of the Xe atom. The binding entropies were not calculated for all mechanisms due to computational cost. For those that were not calculated the entropy was arbitrarily set to zero. This approximation is sound given the corresponding diffusion rates are slow enough that they are not expected to contribute to diffusion under any viable scenario for the binding entropies.

The diffusion rates of $\mathrm{Xe}$ are obtained by combining the migration properties and binding energies/entropies with the trap site fractions and equi- 
librium vacancy concentrations according to Eq. 13. The resulting Arrhenius activation energies $\left(E_{A, a}^{R}\right)$ and pre-exponential factors $\left(D_{A, a}^{R}\right)$ are collected in Table A.6 (see appendix) for the nearly stoichiometric limit. The total diffusivity resolved in the $a-b$ plane $\left(D_{\mathrm{Xe}}^{a a}=D_{\mathrm{Xe}}^{b b}\right)$ and along the $c$ axis $\left(D_{\mathrm{Xe}}^{c c}\right)$ are plotted in Fig. 7a, which also includes the upper and lower bounds for the effective diffusion coefficients in polycrystalline samples. Fig. $7 \mathrm{~b}$ shows the diffusion coefficient for each individual mechanism. The Arrhenius parameters for the polycrystalline bounds are collected in Table 1 .

a)

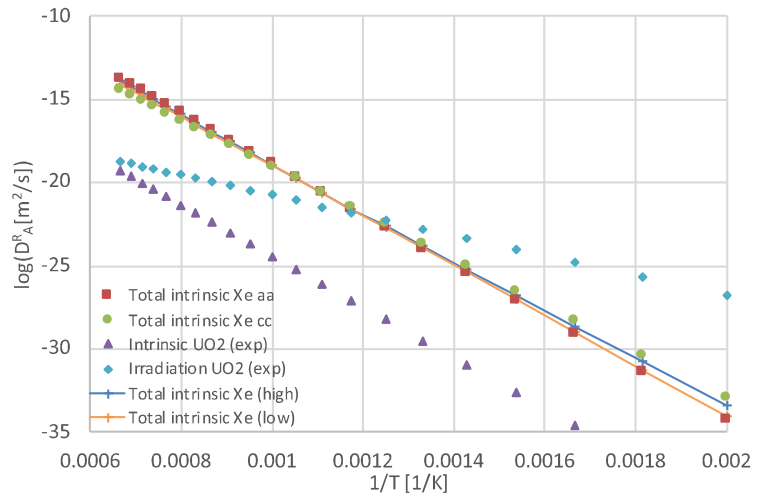

b)

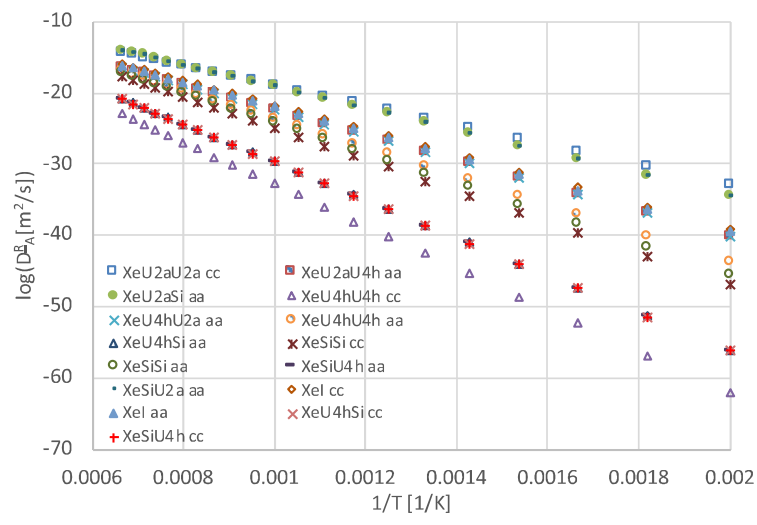

Figure 7: a) The Xe diffusivity tensor components ( $D_{\mathrm{Xe}}^{a a}=$ $D_{\mathrm{Xe}}^{b b}$ and $\left.D_{\mathrm{Xe}}^{c c}\right)$ in nearly stoichiometric $\mathrm{U}_{3} \mathrm{Si}_{2}$. The high and low bounds show the range of possible values in polycrystalline samples. Model predictions based on experimental data for $\mathrm{UO}_{2}$ is also shown as reference [53]. b) Diffusivity tensor components for all the contributing mechanisms in $\mathrm{U}_{3} \mathrm{Si}_{2}$ for the same thermodynamic conditions as in a).

When $\mathrm{U}_{3} \mathrm{Si}_{2}$ is close to exact stoichiometry, the fastest diffusion rate at low temperature occurs for $\mathrm{Xe}$ in a $\mathrm{U} 2 \mathrm{a}$ vacancy moving in the $c$ direction to another U 2a vacancy, see Fig. A.4a of the ap- pendix. The rate-limiting step for Xe migration along the $c$ axis is not the barrier of the Xe atom moving from one vacancy to another, but rather for the vacancy to move from one side of the cluster to the other. This step is faster than detaching the assisting vacancy from the cluster after the Xe atom has moved from the original trap site to the second bound vacancy. That is, the cluster prefers to move as a bound unit. Migrating from one $U$ 2a vacancy to another in the $a-b$ plane involves a hop though a vacant $U$ 4 h or $\mathrm{Si}$ site, as illustrated in Fig A.4b and $\mathrm{c}$ of the appendix. The direct hop to another $\mathrm{U} 2 \mathrm{a}$ vacancy has a much higher barrier. The Si vacancy mechanism is the fastest of the two and at high temperature this mechanism is even faster than diffusion along the $c$ axis. Equivalent rates are obtained for the diffusion mechanisms starting in a $\mathrm{U} 4 \mathrm{~h}$ or Si vacancy and then migrating by binding a $\mathrm{U} 2 \mathrm{a}$ vacancy, consequently those lines overlay each other in the plots. Xe interstitial diffusion is also fast, but still slower than the vacancy mechanisms for nearly stoichiometric $\mathrm{U}_{3} \mathrm{Si}_{2}$. The results for Sirich and U-rich conditions are plotted in Fig. A.7 (see appendix).

\section{Discussion}

redThe diffusion tensors of $\mathrm{U}, \mathrm{Si}$ and $\mathrm{Xe}$ are anisotropic due to the tetragonal crystal structure of $\mathrm{U}_{3} \mathrm{Si}_{2}$. In several cases the $\mathrm{U}_{3} \mathrm{Si}_{2}$ crystal structure also leads to complex mechanisms involving multiple steps and atoms. The relevant steps were identified by enumerating possible pathways by hand and then applying a trial error approach based on the results from NEB calculations. The most noteworthy result is that $\mathrm{U}$ interstitials have a very high diffusivity in the $a-b$ planes of the $\mathrm{U}_{3} \mathrm{Si}_{2}$ crystal structure. Si interstitials also have a high diffusivity in the $a-b$ plane, which is driven by a high concentration at elevated temperatures rather than a very low migration barrier as for uranium interstitials. Xe diffusion occurs preferentially by vacancy mechanisms and the anisotropy is less dramatic than for self-diffusion. Although not explicitly emphasized in the results section, the prediction of diffusion rates obviously carries uncertainties. Known sources of uncertainty include the use of supercells of limited size $(2 \times 2 \times 3)$ for formation and migration energies and even smaller supercells for entropies, approximations of the attempt frequency and the use of the harmonic approximation for phonon properties. There are also uncertainties 
related to the model form. For example, clusters of vacancies or interstitials were not considered and Xe vacancy diffusion mechanisms were limited to a single assisting vacancy. These uncertainties should be kept in mind when using the data presented in this paper for prediction of fuel properties related to the calculated diffusion rates, such as gas release, swelling, microstructure evolution (grain growth) and creep. These properties can also be used for indirect validation of the predictions in the present study together with direct measurements of selfand gas diffusion. However, at this point there is little or no direct data on Xe or self-diffusion and even though there may be some indirect information about diffusion in literature through microstructure evolution and swelling, it is difficult to apply without further developing models that quantitively connect for example models of grain growth, swelling and creep to bulk diffusion of point defects and gas atoms.

Therefore, validation of our predictions is challenging. However, it is interesting and valuable to compare with the corresponding data for $\mathrm{UO}_{2}$ in order to better understand how fission gas behavior will differ in $\mathrm{U}_{3} \mathrm{Si}_{2}$ and $\mathrm{UO}_{2}$. Figs. 5 and 7 plot the predicted self-diffusion and fission gas diffusion coefficients in nearly stoichiometric $\mathrm{U}_{3} \mathrm{Si}_{2}$ against experimental data measured for nearly stoichiometric $\mathrm{UO}_{2}$ [51-53]. Self-diffusion in $\mathrm{U}_{3} \mathrm{Si}_{2}$ is generally much faster than $\mathrm{U}$ diffusion in $\mathrm{UO}_{2}$. The $\mathrm{U}$ interstitial mechanism in the $a-b$ plane is even faster than $\mathrm{O}$ diffusion in $\mathrm{UO}_{2}$, while the corresponding $\mathrm{Si}$ interstitial mechanism is somewhat slower. Xe diffusion is also faster in $\mathrm{U}_{3} \mathrm{Si}_{2}$ than in $\mathrm{UO}_{2}$ under equilibrium conditions (no irradiation). At low temperature radiation-enhanced $\mathrm{Xe}$ diffusion in $\mathrm{UO}_{2}$ exceeds the thermal diffusion rate in $\mathrm{U}_{3} \mathrm{Si}_{2}$. For temperatures that are high enough to anneal the point defects generated by radiation damage, the intrinsic rates also govern diffusion under irradiation. At those temperatures fission gas release to the plenum and/or fission gas collected in gas bubbles is expected to be higher than for a $\mathrm{UO}_{2}$ fuel under the same conditions. The operating temperatures of a $\mathrm{U}_{3} \mathrm{Si}_{2}$ fuel would be lower than for a $\mathrm{UO}_{2}$ because of the higher thermal conductivity of $\mathrm{U}_{3} \mathrm{Si}_{2}$, which makes direct comparison of the impact on fuel performance difficult without carrying out the actual fuel performance simulations. That exercise is left as future work. We do not yet have any prediction of how $\mathrm{U}$ and $\mathrm{Si}$ self-diffusion and Xe diffusion are impacted by irradiation in $\mathrm{U}_{3} \mathrm{Si}_{2}$, but studies employing simulations of ballistic damage with a MEAM U-Si empirical potential [35] are under way.

There are no direct measurements of point defect concentrations in $\mathrm{UO}_{2}$ or $\mathrm{U}_{3} \mathrm{Si}_{2}$. Instead Fig. 8 compares simulations of point defect concentrations in $\mathrm{UO}_{2}[54]$ with the $\mathrm{U}_{3} \mathrm{Si}_{2}$ predictions in Fig. 2 . The range of point defect concentrations and non-stoichiometry are similar between $\mathrm{U}_{3} \mathrm{Si}_{2}$ and $\mathrm{UO}_{2}$. In the model of Ref. [54] $\mathrm{UO}_{2+x}$ reaches $x=0$ slightly above the highest temperature in the plot, while for $\mathrm{U}_{3} \mathrm{Si}_{2+x}$ this point is reached asymptotically at $0 \mathrm{~K}$. This also drives the difference in concentration between point defects in $\mathrm{UO}_{2+x}$ and $\mathrm{U}_{3} \mathrm{Si}_{2+x}$. The reason for the opposite Arrhenius relations for the non-stoichiometry comes from $\mathrm{UO}_{2+x}$ being in equilibrium with $\mathrm{O}_{2}$ gas, which leads to a specific temperature dependence of the O chemical potential, while the chemical potentials of the $\mathrm{U}_{3} \mathrm{Si}_{2+x}$ equilibrium is referenced to solid phases.

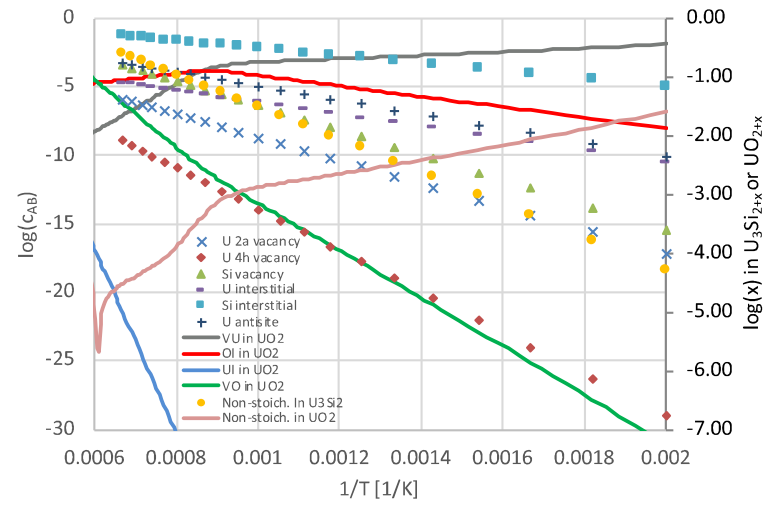

Figure 8: Equilibrium defect concentrations (plotted as concentration (per $\mathrm{U}_{3} \mathrm{Si}_{2}$ or $\mathrm{UO}_{2}$ unit), $c_{A_{B}}$, left-hand axis) and non-stoichiometry ( $x$, right-hand y-axis) in $\mathrm{U}_{3} \mathrm{Si}_{2+x}$ and $\mathrm{UO}_{2+x}$ for nearly stoichiometric conditions. The point defect concentrations in $\mathrm{UO}_{2+x}$ shown as solid lines and taken from M.W.D. Cooper et al. [54].

\section{Conclusions}

Density functional theory (DFT) calculations have been used to investigate $\mathrm{U}$ and $\mathrm{Si}$ self-diffusion and fission gas diffusion (in the form of $\mathrm{Xe}$ ) in $\mathrm{U}_{3} \mathrm{Si}_{2}$, which is one of the main accident tolerant fuel (ATF) candidates. Due to the tetragonal symmetry of $\mathrm{U}_{3} \mathrm{Si}_{2}$, the diffusion coefficients are tensors with unique behavior in the $a-b$ plane and along the $c$ axis of the crystal structure. U self-diffusion is fast 
in the $a-b$ plane through an interstitial mechanism. Although not as fast as U diffusion, the Si interstitial mechanism in the $a-b$ plane also exhibits a high rate compared to other mechanisms. This is in part a consequence of the high concentration of Si interstitials, which also leads to significant nonstoichiometry. Vacancy diffusion mechanisms for both $\mathrm{U}$ and $\mathrm{Si}$ are faster along the $c$ axis than in the $a-b$ plane of the $\mathrm{U}_{3} \mathrm{Si}_{2}$ structure. The low symmetry of $\mathrm{U}_{3} \mathrm{Si}_{2}$ further implies that the diffusion mechanisms are complex and involve multiple steps. The self-diffusion rates in $\mathrm{U}_{3} \mathrm{Si}_{2}$ are faster than $\mathrm{U}$ diffusion in $\mathrm{UO}_{2}$, and the rate of the $\mathrm{U}$ interstitial mechanism is even faster than that of $\mathrm{O}$ diffusion in $\mathrm{UO}_{2}$.

$\mathrm{Xe}$ is predicted to preferentially occupy $\mathrm{U}(\mathrm{U} 2 \mathrm{a})$ vacancies for all thermodynamic conditions. The fastest Xe diffusion mechanisms involve a second assisting vacancy, either a $U 2 a$ vacancy along the $c$ axis or a $\mathrm{Si}$ vacancy in the $a-b$ plane of the $\mathrm{U}_{3} \mathrm{Si}_{2}$ structure. Xe diffusion in $\mathrm{U}_{3} \mathrm{Si}_{2}$ is faster than in $\mathrm{UO}_{2}$ under thermal conditions (no irradiation). At low temperature, radiation-enhanced diffusion in $\mathrm{UO}_{2}$ overtakes the thermal rate in $\mathrm{U}_{3} \mathrm{Si}_{2}$. The effect of irradiation is not yet known for $\mathrm{U}_{3} \mathrm{Si}_{2}$.

\section{Acknowledgements}

This work was funded by the Department of Energy Nuclear Energy Advanced Modeling and Simulation program. This work was carried out in collaboration with the industry led international CARAT program on accident tolerant fuels.

[1] S. Bragg-Sitton, Development of advanced accidenttolerant fuels for commercial LWRs, Nuclear News 57 (2014) 83-91.

[2] K. Terrani, S. Zinkle, L. Snead, Advanced oxidationresistant iron-based alloys for LWR fuel cladding, J. Nucl. Mater. 448 (2014) $420-435$.

[3] H.-G. Kim, J.-H. Yang, W.-J. Kim, Y.-H. Koo, Development Status of Accident-tolerant Fuel for Light Water Reactors in Korea, Nucl. Eng. Technol. 48 (2016) 1 -15 .

[4] M. Tonks, D. Andersson, S. Phillpot, Y. Zhang, R. Williamson, C. Stanek, B. Uberuaga, S. Hayes, Mechanistic materials modeling for nuclear fuel performance, Ann. Nucl. Energy 105 (2017) 11-24.

[5] Y. S. Kim, G. Hofman, J. Rest, A. Robinson, Temperature and dose dependence of fission-gas-bubble swelling in $\mathrm{U}_{3} \mathrm{Si}_{2}$, J. Nucl. Mater. 389 (2009) $443-449$.

[6] X. Guo, J. T. White, A. T. Nelson, A. Migdisov, R. Roback, H. Xu, Enthalpy of formation of $\mathrm{U}_{3} \mathrm{Si}_{2}$ : A high-temperature drop calorimetry study, J. Nucl. Mater. 507 (2018) $44-49$.

[7] U. Carvajal-Nunez, T. Saleh, J. White, B. Maiorov, A. Nelson, Determination of elastic properties of polycrystalline $\mathrm{U}_{3} \mathrm{Si}_{2}$ using resonant ultrasound spectroscopy, J. Nucl. Mater. 498 (2018) 438 - 444.

[8] E. S. Wood, J. White, A. Nelson, Oxidation behavior of U-Si compounds in air from 25 to $1000 \mathrm{C}$, J. Nucl. Mater. 484 (2017) 245 - 257.

[9] S. Middleburgh, R. Grimes, E. Lahoda, C. Stanek, D. Andersson, Non-stoichiometry in $\mathrm{U}_{3} \mathrm{Si}_{2}, \mathrm{~J}$. Nucl. Mater. 482 (2016) $300-305$.

[10] J. White, A. Nelson, J. Dunwoody, D. Byler, K. McClellan, Thermophysical properties of USi to $1673 \mathrm{~K}, \mathrm{~J}$. Nucl. Mater. 471 (2016) 129 - 135.

[11] A. Berche, C. Rado, O. Rapaud, C. Guneau, J. Rogez, Thermodynamic study of the U-Si system, J. Nucl. Mater. 389 (2009) $101-107$.

[12] J. M. Harp, P. A. Lessing, R. E. Hoggan, Uranium silicide pellet fabrication by powder metallurgy for accident tolerant fuel evaluation and irradiation, J. Nucl. Mater. 466 (2015) $728-738$.

[13] D. J. Antonio, K. Shrestha, J. M. Harp, C. A. Adkins, Y. Zhang, J. Carmack, K. Gofryk, Thermal and transport properties of $\mathrm{U}_{3} \mathrm{Si}_{2}$, J. Nucl. Mater. 508 (2018) 154 $-158$.

[14] S. Maskova, K. Miliyanchuk, L. Havela, Hydrogen absorption in $\mathrm{U}_{3} \mathrm{Si}_{2}$ and its impact on electronic properties, J. Nucl. Mater. 487 (2017) $418-423$.

[15] A. Nelson, A. Migdisov, E. S. Wood, C. Grote, $\mathrm{U}_{3} \mathrm{Si}_{2}$ behavior in $\mathrm{H}_{2} \mathrm{O}$ environments: Part II, pressurized water with controlled redox chemistry, J. Nucl. Mater. 500 (2018) $81-91$.

[16] E. S. Wood, J. White, C. Grote, A. Nelson, $\mathrm{U}_{3} \mathrm{Si}_{2}$ behavior in $\mathrm{H}_{2} \mathrm{O}$ : Part I, flowing steam and the effect of hydrogen, J. Nucl. Mater. 501 (2018) $404-412$.

[17] E. Jossou, U. Eduok, N. Y. Dzade, B. Szpunar, J. A. Szpunar, Oxidation behaviour of $\mathrm{U}_{3} \mathrm{Si}_{2}$ : an experimental and first principles investigation, Phys. Chem. Chem. Phys. 20 (2018) 4708-4720.

[18] Y. Miao, K. A. Gamble, D. Andersson, B. Ye, Z.-G. Mei, G. Hofman, A. M. Yacout, Gaseous swelling of $\mathrm{U}_{3} \mathrm{Si}_{2}$ during steady-state LWR operation: A rate theory investigation, Nucl. Eng. Des. 322 (2017) $336-344$.

[19] G. Kresse, J. Hafner, Ab initio molecular dynamics for open-shell transition metals, Phys. Rev. B 48 (1993) 13115-13118.

[20] G. Kresse, J. Furthmüller, Efficiency of ab-initio total energy calculations for metals and semiconductors using a plane-wave basis set, Comp. Mater. Sci. 6 (1996) 1550 .

[21] G. Kresse, J. Furthmüller, Efficient iterative schemes for ab initio total-energy calculations using a planewave basis set, Phys. Rev. B 54 (1996) 11169-11186.

[22] G. Kresse, D. Joubert, From ultrasoft pseudopotentials to the projector augmented-wave method, Phys. Rev. B 59 (1999) 1758-1775.

[23] P. E. Blöchl, Projector augmented-wave method, Phys. Rev. B 50 (1994) 17953-17979.

[24] J. Z. V. I. Anisimov, O. K. Andersen, Band theory and Mott insulators: Hubbard $U$ instead of Stoner $I$, Phys. Rev. B 44 (1991) 943

[25] A. I. Liechtenstein, V. I. Anisimov, J. Zaanen, Densityfunctional theory and strong interactions: Orbital ordering in Mott-Hubbard insulators, Phys. Rev. B 52 (1995) 5467.

[26] S. L. Dudarev, D. N. Manh, A. P. Sutton, Effect of Mott-Hubbard correlations on the electronic structure and structural stability of uranium dioxide, Phil. Mag. 
75 (1997) 613.

[27] M. J. Noordhoek, T. M. Besmann, D. Andersson, S. C. Middleburgh, A. Chernatynskiy, Phase equilibria in the U-Si system from first-principles calculations, J. Nucl. Mater. 479 (2016) 216 - 223

[28] M. J. Noordhoek, D. Andersson, T. M. Besmann, Structure determination and stability for $\mathrm{Pa}-\mathrm{Si}, \mathrm{Np}-\mathrm{Si}$ and U-X-Si (X=Mo, Th, Np) phases from first-principles, J. Nucl. Mater. 479 (2016) $593-607$.

[29] T. Wang, N. Qiu, X. Wen, Y. Tian, J. He, K. Luo, X. Zha, Y. Zhou, Q. Huang, J. Lang, S. Du, Firstprinciples investigations on the electronic structures of $\mathrm{U}_{3} \mathrm{Si}_{2}$, J. Nucl. Mater. 469 (2016) $194-199$.

[30] S. Middleburgh, A. Claisse, D. Andersson, R. Grimes, P. Olsson, S. Makov, Solution of hydrogen in accident tolerant fuel candidate material: $\mathrm{U}_{3} \mathrm{Si}_{2}, \mathrm{~J}$. Nucl. Mater. 501 (2018) $234-237$.

[31] D. Lopes, V. Kocevski, T. Wilson, E. Moore, T. Besmann, Stability of $\mathrm{U}_{5} \mathrm{Si}_{4}$ phase in U-Si system: Crysta structure prediction and phonon properties using firstprinciples calculations, J. Nucl. Mater. 510 (2018) 331 -336 .

[32] K. Remschnig, T. L. Bihan, H. Nol, P. Rogl, Structura chemistry and magnetic behavior of binary uranium silicides, J. Solid State Chem. 97 (1992) 391 - 399.

[33] A. Zunger, S.-H. Wei, L. G. Ferreira, J. E. Bernard, Special quasirandom structures, Phys. Rev. Lett. 65 (1990) 353-356.

[34] G. Henkelman, B. P. Uberuaga, H. Jonsson, A climbing image nudged elastic band method for finding saddle points and minimum energy paths, J. Chem. Phys. 113 (2000) 9901.

[35] B. Beeler, M. Baskes, D. Andersson, M. W. Cooper, Y. Zhang, A modified Embedded-Atom Method interatomic potential for uranium-silicide, J. Nucl. Mater. 495 (2017) $267-276$.

[36] Y. Mishin, M. R. Sorensen, A. F. Voter, Calculation of point-defect entropy in metals, Phil. Mag. 81 (2001) 2591-2612.

[37] A. Togo, I. Tanaka, First principles phonon calculations in materials science, Scr. Mater. 108 (2015) 1-5.

[38] G. H. Vineyard, Frequency factors and isotope effects in solid state rate processes, J. Phys. Chem. Solids 3 (1957) 121-127

[39] J. D. H. Nol, V. Queneau, P. Colomb., Characterization of a new binary uranium silicide $\mathrm{U}_{5} \mathrm{Si}_{4}$, Conference on strongly correlated electron systems-SCES98 (1998) 92

[40] T. L. Bihan, H. Nol, P. Rogl, Crystal structure of the uranium monosilicide USi, J. Alloy Compd. 240 (1996) $128-133$.

[41] P. G. Shewmon, Diffusion in Solids, McGraw-Hill, New York, 1989

[42] D. Andersson, P. Garcia, X.-Y. Liu, G. Pastore, M. Tonks, P. Millett, B. Dorado, D. Gaston, D. Andrs, R. Williamson, R. Martineau, B. Uberuaga, C. Stanek, Atomistic modeling of intrinsic and radiation-enhanced fission gas (Xe) diffusion in: Implications for nuclear fuel performance modeling, J. Nucl. Mater. 451 (2014) 225-242.

[43] R. Perriot, X. Y. Liu, C. R. Stanek, D. A. Andersson, Diffusion of $\mathrm{Zr}, \mathrm{Ru}, \mathrm{Ce}, \mathrm{Y}, \mathrm{La}, \mathrm{Sr}$ and $\mathrm{Ba}$ fission products in $\mathrm{UO}_{2}$, J. Nucl. Mater. 459 (2015) 9096.

[44] D. A. Andersson, B. P. Uberuaga, P. V. Nerikar C. Unal, C. R. Stanek, Phys. Rev. B 84 (2011) 054105.

[45] D. A. Andersson, M. R. Tonks, L. Casillas, S. Vyas,
P. Nerikar, B. P. Uberuaga, C. R. Stanek, Multiscale simulation of xenon diffusion and grain boundary segregation in $\mathrm{UO}_{2}$, J. Nucl. Mater. 462 (2015) $15-25$.

[46] E. Vathonne, D. A. Andersson, M. Freyss, R. Perriot, M. W. D. Cooper, C. R. Stanek, M. Bertolus, Determination of Krypton Diffusion Coefficients in Uranium Dioxide Using Atomic Scale Calculations, Inorg. Chem. 56 (2017) 125-137.

[47] A. Claisse, T. Schuler, D. A. Lopes, P. Olsson, Transport properties in dilute $\mathrm{UN}(X)$ solid solutions $(X=$ Xe, Kr), Phys. Rev. B 94 (2016) 174302.

[48] G. Grimvall, Thermophysical Properties of Materials, North Holland, 1999.

[49] J. Sanchez, F. Ducastelle, D. Gratias, Generalized cluster description of multicomponent systems, Physica A 128 (1984) $334-350$.

[50] D. D. Fontaine, Cluster Approach to Order-Disorder Transformations in Alloys, Sol. Stat. Phys. 47 (1994) $33-176$.

[51] A. C. S. Sabioni, W. B. Ferraz, F. Millot, First study of uranium self-diffusion in $\mathrm{UO}_{2}$ by SIMS, J. Nucl. Mater. 257 (1998) 180.

[52] A. Auskern, J. Belle, Oxygen ion self-diffusion in uranium dioxide, J. Nucl. Mater. 3 (1961) $267-276$.

[53] J. A. Turnbull, C. A. Friskney, J. R. Findlay, F. A. Johnson, A. J. Walter, The diffusion coefficients of gaseous and volatile species during the irradiation of uranium dioxide, J. Nucl. Mater. 107 (1982) 168-184.

[54] M. Cooper, S. Murphy, D. Andersson, The defect chemistry of $\mathrm{UO}_{2 \pm x}$ from atomistic simulations, J. Nucl. Mater. 504 (2018) $251-260$

\section{Appendix A. Thermodynamic properties and kinetic properties of $\mathrm{Xe}$ and point defects in $\mathrm{U}_{3} \mathrm{Si}_{2}$}

The appendix collects tables of data discussed in the body of the manuscript as well as additional figures depicting thermodynamic and kinetic relations for Si-rich and U-rich conditions in $\mathrm{U}_{3} \mathrm{Si}_{2}$. The nearly stoichiometric cases are illustrated in the main body of the manuscript. The appendix also contains schematics of the Xe diffusion mechanisms. Tables and figures are ordered according to their appearance in the article. 


\begin{tabular}{lccclccccc}
\hline \hline & \multicolumn{3}{c}{ Energies (eV) } & \multicolumn{3}{c}{ Entropies $\left(k_{B}\right)$} & \multicolumn{2}{c}{ Volumes $\left(\AA^{3}\right)$} \\
\hline & Stoich. & Si-rich & U-rich & & Stoich. & Si-rich & U-rich & & $\mathrm{U}_{3} \mathrm{Si}_{2}$ \\
\hline$e_{\mathrm{U}}$ & -9.79 & -9.83 & -9.79 & $s_{\mathrm{U}}$ & -3.11 & -1.30 & -3.41 & N/A & N/A \\
$e_{\mathrm{Si}}$ & -6.24 & -6.19 & -6.26 & $s_{\mathrm{Si}}$ & -5.79 & -8.05 & -4.88 & N/A & N/A \\
\hline$E_{\mathrm{V}_{\mathrm{U} 2 \mathrm{a}}, f}$ & 1.69 & 1.65 & 1.69 & $S_{\mathrm{V}_{\mathrm{U} 2 \mathrm{a}}, f}$ & 0.45 & 2.26 & 0.15 & $\Delta V_{\mathrm{V}_{\mathrm{U} 2 \mathrm{a}}}$ & -4.17 \\
$E_{\mathrm{V}_{\mathrm{U} 4 \mathrm{~h}, f}}$ & 3.00 & 2.96 & 3.00 & $S_{\mathrm{V}_{\mathrm{U}_{4}, f}}$ & 2.89 & 4.70 & 2.59 & $\Delta V_{\mathrm{V}_{\mathrm{U} 4 \mathrm{~h}}}$ & -2.37 \\
$E_{\mathrm{V}_{\mathrm{Si}, f}}$ & 1.79 & 1.84 & 1.77 & $S_{\mathrm{V}_{\mathrm{Si}}, f}$ & 6.28 & 4.01 & 7.19 & $\Delta V_{\mathrm{V}_{\mathrm{Si}}}$ & -7.81 \\
$E_{\mathrm{U}_{i}, f}$ & 0.87 & 0.91 & 0.86 & $S_{\mathrm{U}_{i}, f}$ & -3.15 & -4.96 & -2.85 & $\Delta V_{\mathrm{U}_{i}}$ & 0.07 \\
$E_{\mathrm{Si}_{i}, f}$ & 0.55 & 0.50 & 0.57 & $S_{\mathrm{Si}_{i}, f}$ & 2.19 & 4.45 & 1.28 & $\Delta V_{\mathrm{Si}_{i}}$ & 4.09 \\
$E_{\mathrm{U}_{\mathrm{Si}}, f}$ & 1.02 & 1.11 & 1.00 & $S_{\mathrm{U}_{\mathrm{Si}}, f}$ & 1.32 & -2.75 & 2.53 & $\Delta V_{\mathrm{U}_{\mathrm{Si}}}$ & 0.81 \\
\hline \hline
\end{tabular}

Table A.1: U and Si point defect formation energies and entropies calculated for the three thermodynamic limits defined in Sec. 2.2. The partial energy and entropy defining the equilibrium conditions are also listed. Finally, the defect volumes used to estimate the formation entropies are shown $(\Delta V)$. The defect volumes do not have any dependence on non-stoichiometry.

\begin{tabular}{lcccccccc}
\hline \hline & \multicolumn{3}{c}{ Energies (eV) } & \multicolumn{3}{c}{ Pre-exponential factors $\left(\mathrm{m}^{2} / \mathrm{s}\right)$} \\
\hline & $E_{A, m}^{a a}$ & $E_{A, m}^{c c}$ & $E_{A, a}^{a a}$ & $E_{A, a}^{c c}$ & $D_{A, 0}^{a a}$ & $D_{A, 0}^{c c}$ & $D_{A, a}^{a a}$ & $D_{A, a}^{c c}$ \\
\hline $\mathrm{V}_{\mathrm{U} 2 \mathrm{a}}$ & 1.71 & 1.21 & 3.39 & 2.89 & $2.20 \cdot 10^{-6}$ & $2.13 \cdot 10^{-7}$ & $3.45 \cdot 10^{-6}$ & $3.35 \cdot 10^{-6}$ \\
$\mathrm{~V}_{\mathrm{U} 4 \mathrm{~h}}$ & 0.40 & 3.30 & 3.39 & 6.30 & $1.92 \cdot 10^{-7}$ & $1.52 \cdot 10^{-6}$ & $3.45 \cdot 10^{-6}$ & $2.73 \cdot 10^{-5}$ \\
$\mathrm{~V}_{\mathrm{Si}}$ & 2.37 & 2.44 & 4.17 & 4.23 & $1.76 \cdot 10^{-6}$ & $1.52 \cdot 10^{-6}$ & $9.39 \cdot 10^{-4}$ & $8.13 \cdot 10^{-4}$ \\
$\mathrm{U}_{i}$ & 0.31 & 2.56 & 1.18 & 3.43 & $2.18 \cdot 10^{-5}$ & $1.52 \cdot 10^{-6}$ & $9.32 \cdot 10^{-7}$ & $6.50 \cdot 10^{-8}$ \\
$\mathrm{Si}_{i}$ & 1.80 & 2.91 & 2.35 & 3.46 & $2.69 \cdot 10^{-6}$ & $6.08 \cdot 10^{-6}$ & $2.40 \cdot 10^{-5}$ & $5.43 \cdot 10^{-5}$ \\
\hline \hline
\end{tabular}

Table A.2: Migration barriers $\left(E_{A, m}^{R}\right)$, activation energies for self-diffusion $\left(E_{A, a}^{R}\right.$, for nearly stoichiometric $\left.\mathrm{U}_{3} \mathrm{Si}_{2}\right)$, preexponential factors for migration $\left(D_{A, 0}^{R}\right)$ and pre-exponential factors for self-diffusion $\left(D_{A, a}^{a a}\right.$, for nearly stoichiometric $\left.\mathrm{U}_{3} \mathrm{Si}_{2}\right)$ of $\mathrm{U}$ and $\mathrm{Si}$ in $\mathrm{U}_{3} \mathrm{Si}_{2}$ by vacancy and interstitial mechanisms.

\begin{tabular}{|c|c|c|c|c|c|c|}
\hline & $\nu_{A_{B}}^{a a}\left(\mathrm{~s}^{-1}\right)$ & $\nu_{A_{B}}^{c c}\left(\mathrm{~s}^{-1}\right)$ & $d_{A_{B}}^{a a}(\AA)$ & $d_{A_{B}}^{c c}(\AA)$ & $Z_{A_{B}}^{a a}$ & $Z_{A_{B}}^{c c}$ \\
\hline $\mathrm{V}_{\mathrm{U} 2 \mathrm{a}}$ & $8.18 \cdot 10^{12}$ & $1.40 \cdot 10^{13}$ & 5.18 & 3.90 & 4 & 2 \\
\hline $\mathrm{V}_{\mathrm{U} 4 \mathrm{~h}}$ & $7.16 \cdot 10^{11}$ & $1 \cdot 10^{13 *}$ & 5.18 & 3.90 & 4 & 2 \\
\hline $\mathrm{V}_{\mathrm{Si}}$ & $1.00 \cdot 10^{13 *}$ & $1 \cdot 10^{13 *}$ & 4.19 & 3.90 & 4 & 2 \\
\hline $\mathrm{U}_{i}$ & $1.51 \cdot 10^{14}$ & $1 \cdot 10^{14 *}$ & 3.80 & 3.90 & 4 & 2 \\
\hline $\mathrm{Si}_{i}$ & $1.00 \cdot 10^{13 *}$ & $1 \cdot 10^{13 *}$ & 5.18 & 3.90 & 4 & 2 \\
\hline $\mathrm{Xe}_{\mathrm{U} 2 \mathrm{aU} 2 \mathrm{a}}$ & $\mathrm{N} / \mathrm{A}$ & $1.00 \cdot 10^{13 *}$ & $\mathrm{~N} / \mathrm{A}$ & 3.90 & 4 & 2 \\
\hline $\mathrm{Xe}_{\mathrm{U} 2 \mathrm{aU} 4 \mathrm{~h}}$ & $1.00 \cdot 10^{13 *}$ & $1.00 \cdot 10^{13 *}$ & 5.18 & 3.90 & 4 & 2 \\
\hline $\mathrm{Xe}_{\mathrm{U} 2 \mathrm{aSi}}$ & $1.00 \cdot 10^{13 *}$ & $\mathrm{~N} / \mathrm{A}$ & 5.18 & $\mathrm{~N} / \mathrm{A}$ & 4 & 2 \\
\hline $\mathrm{Xe}_{\mathrm{U} 4 \mathrm{hU} 2 \mathrm{a}}$ & $1.00 \cdot 10^{13 *}$ & $1.00 \cdot 10^{13 *}$ & 5.18 & 3.90 & 4 & 2 \\
\hline $\mathrm{Xe}_{\mathrm{U} 4 \mathrm{hU} 4 \mathrm{~h}}$ & $\mathrm{~N} / \mathrm{A}$ & $1.00 \cdot 10^{13 *}$ & $\mathrm{~N} / \mathrm{A}$ & 3.90 & 4 & 2 \\
\hline $\mathrm{Xe}_{\mathrm{U} 4 \mathrm{hSi}}$ & $1.00 \cdot 10^{13 *}$ & $\mathrm{~N} / \mathrm{A}$ & 4.19 & $\mathrm{~N} / \mathrm{A}$ & 4 & 2 \\
\hline $\mathrm{Xe}_{\mathrm{SiU} 2 \mathrm{a}}$ & $1.00 \cdot 10^{13 *}$ & $\mathrm{~N} / \mathrm{A}$ & 5.18 & $\mathrm{~N} / \mathrm{A}$ & 4 & 2 \\
\hline $\mathrm{Xe}_{\mathrm{SiU} 4 \mathrm{~h}}$ & $1.00 \cdot 10^{13 *}$ & $\mathrm{~N} / \mathrm{A}$ & 4.19 & $\mathrm{~N} / \mathrm{A}$ & 4 & 2 \\
\hline $\mathrm{Xe}_{\mathrm{SiSi}}$ & $1.00 \cdot 10^{13 *}$ & $1.00 \cdot 10^{13 *}$ & 4.19 & 3.90 & 4 & 2 \\
\hline $\mathrm{Xe}_{i}$ & $1.00 \cdot 10^{14 *}$ & $1.00 \cdot 10^{14 *}$ & 3.80 & 3.90 & 4 & 2 \\
\hline
\end{tabular}

Table A.3: The attempt frequencies $\left(\nu_{A_{B}}^{R}=\nu_{A_{B}, 0}^{R} \exp \left(S_{A_{B}, m}^{R}\right)\right)$ the jump distance $\left(d_{A_{B}}^{R}\right)$ and the number of (equivalent) neighboring sites $\left(Z_{A_{B}}^{R}\right)$ defining $D_{A_{B}, 0}^{R}$ for self-diffusion and Xe diffusion. The superscript * indicates estimates. 


\begin{tabular}{|c|c|c|c|c|c|c|c|c|c|}
\hline & \multicolumn{4}{|c|}{ Incorporation energies (eV) } & \multicolumn{3}{|c|}{ Incorporation entropies $\left(k_{B}\right)$} & \multicolumn{2}{|c|}{ Volumes $\left(\AA^{3}\right)$} \\
\hline & Stoich. & Si-rich & U-rich & & Stoich. & Si-rich & U-rich & & $\mathrm{U}_{3} \mathrm{Si}_{2}$ \\
\hline$E_{\mathrm{Xe}_{\mathrm{U} 2 \mathrm{a}}, i}$ & 3.24 & 3.24 & 3.24 & $S_{\mathrm{Xe}_{\mathrm{U} 2 \mathrm{a}}, i}$ & -1.72 & -1.72 & -1.72 & $\Delta V_{\mathrm{Xe}_{\mathrm{U} 2 \mathrm{a}}}$ & 16.39 \\
\hline$E_{\mathrm{Xe}_{\mathrm{U} 4 \mathrm{~h}}, i}$ & 3.14 & 3.14 & 3.14 & $S_{\mathrm{Xe}_{\mathrm{U} 4 \mathrm{~h}}, i}$ & -3.37 & -3.37 & -3.37 & $\Delta V_{\mathrm{Xe}_{\mathrm{U} 4 \mathrm{~h}}}$ & 22.66 \\
\hline$E_{\mathrm{Xe}_{\mathrm{Si}}, i}$ & 3.26 & 3.26 & 3.26 & $S_{\mathrm{Xe}_{\mathrm{Si}}, i}$ & -9.16 & -9.16 & -9.16 & $\Delta V_{\mathrm{Xe}_{\mathrm{Si}}}$ & 21.00 \\
\hline$E_{\mathrm{Xe}_{i}, i}$ & 5.36 & 5.36 & 5.36 & $S_{\mathrm{Xe}_{i}, i}$ & 0.16 & 0.16 & 0.16 & $\Delta V_{\mathrm{Xe}_{i}}$ & 15.49 \\
\hline & \multicolumn{3}{|c|}{ Solution energies $(\mathrm{eV})$} & & \multicolumn{3}{|c|}{ Solution entropies $\left(k_{B}\right)$} & & \\
\hline$E_{\mathrm{XeU2a}_{\mathrm{U}} \cdot s}$ & 4.92 & 4.88 & 4.93 & $S_{\mathrm{Xe}}$ & -1.27 & 0.54 & -1.57 & & \\
\hline$E_{\mathrm{Xe}_{\mathrm{Uh}}, s}$ & 6.14 & 6.10 & 6.15 & $S_{\mathrm{Xe}_{\mathrm{U} / \mathrm{h}}, s}$ & -0.48 & 1.33 & -0.78 & & \\
\hline$E_{\mathrm{Xe}_{\mathrm{Si}_{\mathrm{i}}, s}}$ & 5.05 & 5.10 & 5.03 & $S_{\mathrm{Xe}_{\mathrm{Si}}, s}$ & -2.88 & -5.14 & -1.97 & & \\
\hline$E_{\mathrm{Xe}_{i}, s}$ & 5.36 & 5.36 & 5.36 & $S_{\mathrm{Xe}_{i}, s}$ & 0.16 & 0.16 & 0.16 & & \\
\hline
\end{tabular}

Table A.4: The Xe incorporation $\left(E_{\mathrm{Xe}_{X}, i}, S_{\mathrm{Xe}_{X}, i}\right)$ and solution $\left(E_{\mathrm{Xe}_{X}, s}, S_{\mathrm{Xe}_{X}, s}\right)$ energies and entropies for the nearly stoichiometric, Si-rich and U-rich thermodynamic limits outlined in Sec. 2.2. The defect volumes are also listed.

\begin{tabular}{|c|c|c|c|c|c|}
\hline & \multicolumn{2}{|c|}{$\overline{\text { Energies (eV) }}$} & \multicolumn{2}{|c|}{ Entropies $\left(\mathrm{k}_{B}\right)$} & Volumes $\left(\AA^{3}\right)$ \\
\hline & $E_{\mathrm{X}_{\mathrm{S}}}^{a a}$ & $E_{\mathrm{Y}_{0, h}}^{c c}$ & $S_{X_{Y}}^{a a}$ & $S_{\mathrm{X}_{0}}^{c c}$ & $\Delta V_{\mathrm{Xex}}$ \\
\hline $\mathrm{Xe}_{\mathrm{U} 2 \mathrm{aU} 2 \mathrm{a}}$ & $\mathrm{N} / \mathrm{A}$ & -0.49 & $\mathrm{~N} / \mathrm{A}$ & -0.71 & 17.37 \\
\hline $\mathrm{Xe}_{\mathrm{U} 2 \mathrm{aU} 4 \mathrm{~h}}$ & -1.14 & -1.14 & -2.62 & -2.62 & 17.31 \\
\hline $\mathrm{Xe}_{\mathrm{U} 2 \mathrm{aSi}}$ & -1.23 & $\mathrm{~N} / \mathrm{A}$ & -2.31 & $\mathrm{~N} / \mathrm{A}$ & 14.08 \\
\hline $\mathrm{Xe}_{\mathrm{U} 4 \mathrm{hU} 2 \mathrm{a}}$ & -1.05 & -1.05 & -0.97 & -0.97 & 17.31 \\
\hline $\mathrm{Xe}_{\mathrm{U} 4 \mathrm{hU} 4 \mathrm{~h}}$ & -0.56 & -0.47 & $0.00^{*}$ & $0.00^{*}$ & $\mathrm{~N} / \mathrm{A}$ \\
\hline $\mathrm{Xe}_{\mathrm{U} 4 \mathrm{hSi}}$ & -1.59 & -1.59 & $-5.79^{*}$ & $-5.79^{*}$ & $\mathrm{~N} / \mathrm{A}$ \\
\hline $\mathrm{Xe}_{\mathrm{SiU} 2 \mathrm{a}}$ & -0.68 & $\mathrm{~N} / \mathrm{A}$ & 5.13 & $\mathrm{~N} / \mathrm{A}$ & 14.08 \\
\hline $\mathrm{Xe}_{\mathrm{SiU} 4 \mathrm{~h}}$ & -1.70 & -1.70 & $0.00^{*}$ & $0.00^{*}$ & $\mathrm{~N} / \mathrm{A}$ \\
\hline $\mathrm{Xe}_{\mathrm{SiSi}}$ & 0.048 & 0.12 & $0.00^{*}$ & $0.00^{*}$ & $\mathrm{~N} / \mathrm{A}$ \\
\hline $\mathrm{Xe}_{i}$ & 0.00 & 0.00 & 0.00 & 0.00 & 15.49 \\
\hline
\end{tabular}

Table A.5: The binding energies $\left(E_{\mathrm{Xe}_{X}, b}^{R}\right)$ and entropies $\left(S_{\mathrm{Xe}_{X}, b}^{R}\right)$ for the the defects enabling diffusion of Xe through vacancy or interstitial mechanisms. * indicates that the value was not calculated and either set to zero or calculated form an inverse cluster for which the binding entropy was set to zero (e.g., $\mathrm{Xe}_{\mathrm{SiU} 4 \mathrm{~h}}$ and $\left.\mathrm{Xe}_{\mathrm{U} 4 \mathrm{hSi}}\right)$. The defect volumes $\left(\Delta V_{\mathrm{Xe}}\right)$ used to calculate the entropies are also listed. N/A for the volumes means that the corresponding entropy was not calculated and thus the defect volume was not needed for the analysis.

\begin{tabular}{|c|c|c|c|c|c|c|c|c|}
\hline & \multicolumn{4}{|c|}{ Energies $(\mathrm{eV})$} & \multicolumn{4}{|c|}{ Pre-exponentials $\left(\mathrm{m}^{2} / \mathrm{s}\right)$} \\
\hline & $E_{\mathrm{Xe}_{X}, m}^{a a}$ & $E_{\mathrm{Xe}_{X}, m}^{c c}$ & $E_{A, a}^{a a}$ & $E_{A, a}^{c c}$ & $D_{\mathrm{Xe}_{X}, 0}^{a a}$ & $D_{\mathrm{Xe}_{X}, 0}^{c c}$ & $D_{A, a}^{a a}$ & $D_{A, a}^{c c}$ \\
\hline $\mathrm{Xe}_{\mathrm{U} 2 \mathrm{aU} 2 \mathrm{a}}$ & $\mathrm{N} / \mathrm{A}$ & 1.68 & $\mathrm{~N} / \mathrm{A}$ & 2.75 & $\mathrm{~N} / \mathrm{A}$ & $1.52 \cdot 10^{-6}$ & $\mathrm{~N} / \mathrm{A}$ & $5.91 \cdot 10^{-6}$ \\
\hline $\mathrm{Xe}_{\mathrm{U} 2 \mathrm{aU} 4 \mathrm{~h}}$ & 1.79 & 1.79 & 3.51 & 3.51 & $2.69 \cdot 10^{-6}$ & $1.52 \cdot 10^{-6}$ & $1.76 \cdot 10^{-5}$ & $1.33 \cdot 10^{-5}$ \\
\hline $\mathrm{Xe}_{\mathrm{U} 2 \mathrm{aSi}}$ & 2.61 & $\mathrm{~N} / \mathrm{A}$ & 3.05 & $\mathrm{~N} / \mathrm{A}$ & $5.18 \cdot 10^{-7}$ & $\mathrm{~N} / \mathrm{A}$ & $1.39 \cdot 10^{-4}$ & $\mathrm{~N} / \mathrm{A}$ \\
\hline $\mathrm{Xe}_{\mathrm{U} 4 \mathrm{hU} 2 \mathrm{a}}$ & 1.79 & 1.79 & 3.51 & 3.51 & $2.69 \cdot 10^{-6}$ & $1.52 \cdot 10^{-6}$ & $1.76 \cdot 10^{-5}$ & $1.33 \cdot 10^{-5}$ \\
\hline $\mathrm{Xe}_{\mathrm{U} 4 \mathrm{hU} 4 \mathrm{~h}}$ & 0.47 & 2.20 & 4.20 & 5.82 & $1.45 \cdot 10^{-6}$ & $1.52 \cdot 10^{-6}$ & $2.86 \cdot 10^{-4}$ & $3.01 \cdot 10^{-4}$ \\
\hline $\mathrm{Xe}_{\mathrm{U}} 4 \mathrm{hSi}$ & $3.96^{* *}$ & $3.96^{* *}$ & $5.26^{* *}$ & $5.26^{* *}$ & $5.76 \cdot 10^{-4}$ & $2.73 \cdot 10^{-5}$ & $3.16 \cdot 10^{-5 * *}$ & $1.82 \cdot 10^{-5}$ \\
\hline $\mathrm{Xe}_{\mathrm{SiU} 2 \mathrm{a}}$ & 2.04 & $\mathrm{~N} / \mathrm{A}$ & 3.05 & $\mathrm{~N} / \mathrm{A}$ & $5.18 \cdot 10^{-7}$ & $\mathrm{~N} / \mathrm{A}$ & $1.38 \cdot 10^{-4}$ & $\mathrm{~N} / \mathrm{A}$ \\
\hline $\mathrm{Xe}_{\mathrm{SiU} 4 \mathrm{~h}}$ & $3.96^{* *}$ & $3.96^{* *}$ & $5.26^{* *}$ & $5.26^{* *}$ & $1.76 \cdot 10^{-6}$ & $2.73 \cdot 10^{-5}$ & $3.16 \cdot 10^{-5 * *}$ & $1.82 \cdot 10^{-5}$ \\
\hline $\mathrm{Xe}_{\mathrm{SiSi}}$ & $2.33^{* *}$ & $2.32^{* *}$ & $4.17^{* *}$ & $4.23^{* *}$ & $1.76 \cdot 10^{-6}$ & $1.52 \cdot 10^{-6}$ & $9.39 \cdot 10^{-4 * *}$ & $8.13 \cdot 10^{-4 * *}$ \\
\hline $\mathrm{Xe}_{i}$ & 3.20 & 3.13 & 3.50 & 3.44 & $1.44 \cdot 10^{-6}$ & $1.52 \cdot 10^{-6}$ & $3.03 \cdot 10^{-5}$ & $3.18 \cdot 10^{-5}$ \\
\hline
\end{tabular}

Table A.6: The barriers $\left(E_{\mathrm{Xe}_{X}, m}^{R}\right)$ and pre-exponential factors $\left(D_{\mathrm{Xe}_{X}, 0}^{R}\right)$ for Xe diffusion in nearly stoichiometric $\mathrm{U}_{3} \mathrm{Si}_{2}$ by vacancy and interstitial mechanisms as well as the total Arrhenius activation energy $\left(E_{A, a}^{R}\right)$ and pre-exponential factor $\left(D_{A, a}^{R}\right)$. ** indicates diffusion by detachment. 
a)

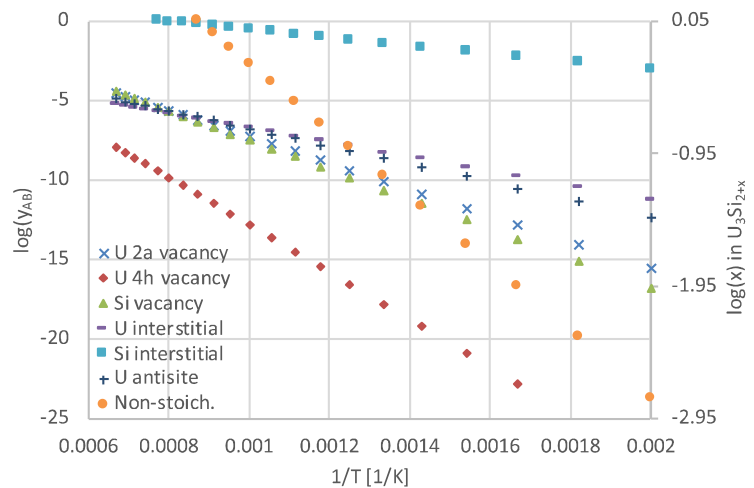

b)

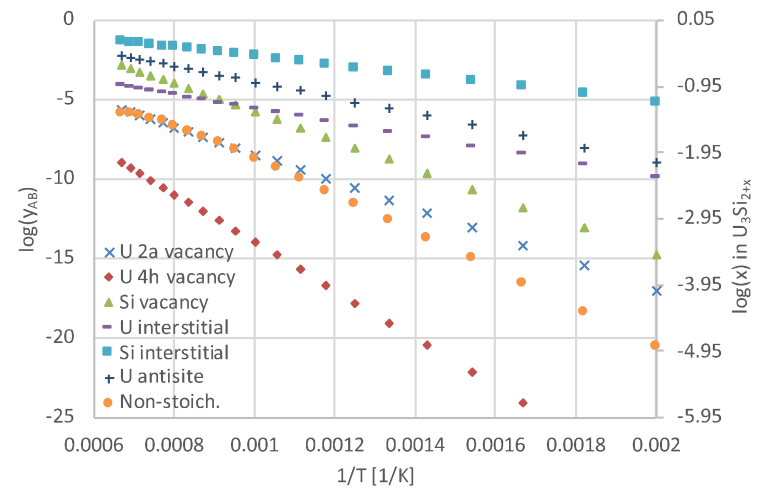

Figure A.1: Equilibrium defect concentrations (plotted as site fractions, $y_{A_{B}}$, left-hand axis) and non-stoichiometry ( $x$, righthand $\mathrm{y}$-axis) in $\mathrm{U}_{3} \mathrm{Si}_{2+x}$ for a) $\mathrm{Si}$ and b) U-rich conditions in $\mathrm{U}_{3} \mathrm{Si}_{2}$.

a)

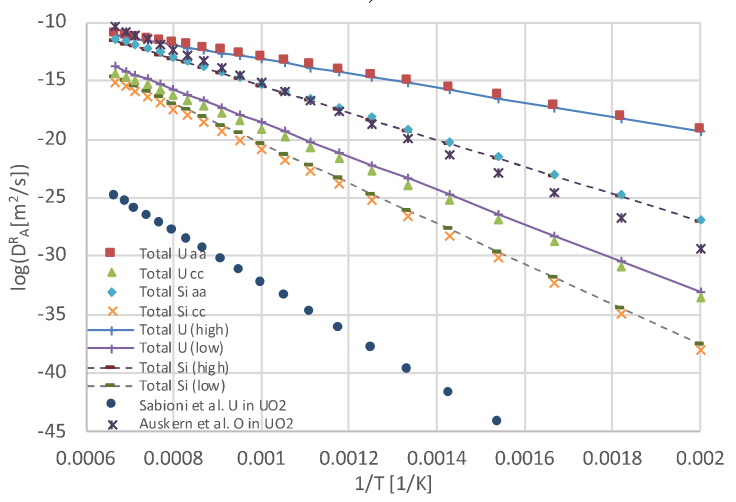

b)

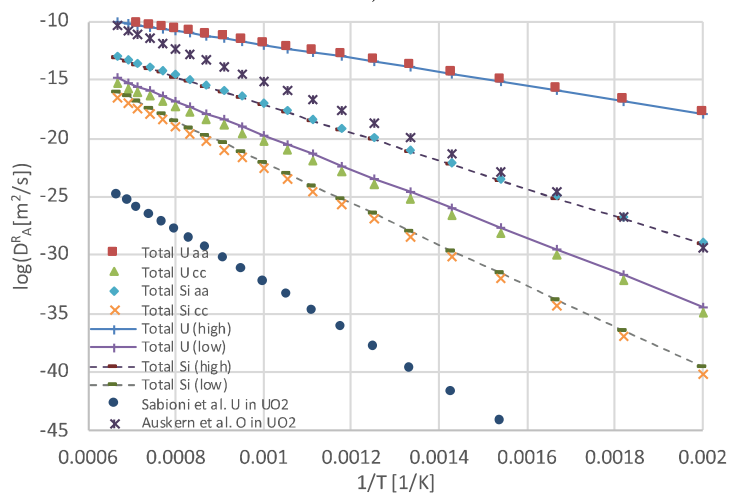

Figure A.2: a) The $D_{A}^{a a}=D_{A}^{b b}$ and $D_{A}^{c c}\left(A=\mathrm{U}\right.$ or $\mathrm{Si}$ ) tensor components for self-diffusion of $\mathrm{U}_{\text {and }} \mathrm{Si}_{\text {in }} \mathrm{U}_{3} \mathrm{Si}_{2}$ for $\mathrm{Si}$-rich conditions. The high and low bounds show the range of possible values in polycrystalline samples. The predictions for $\mathrm{U}_{3} \mathrm{Si}_{2}$ are compared to the experimental data for self-diffusion of $\mathrm{U}[51]$ and $\mathrm{O}$ in $\mathrm{UO}_{2}[52]$. b) The same as a) but for U-rich conditions.

a)

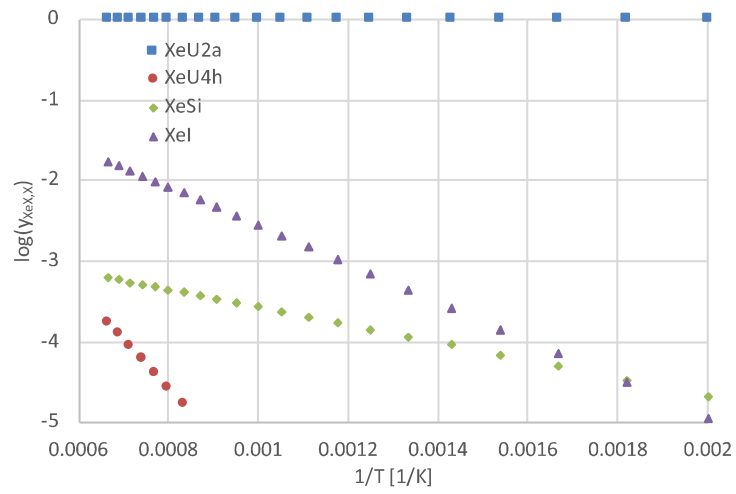

b)

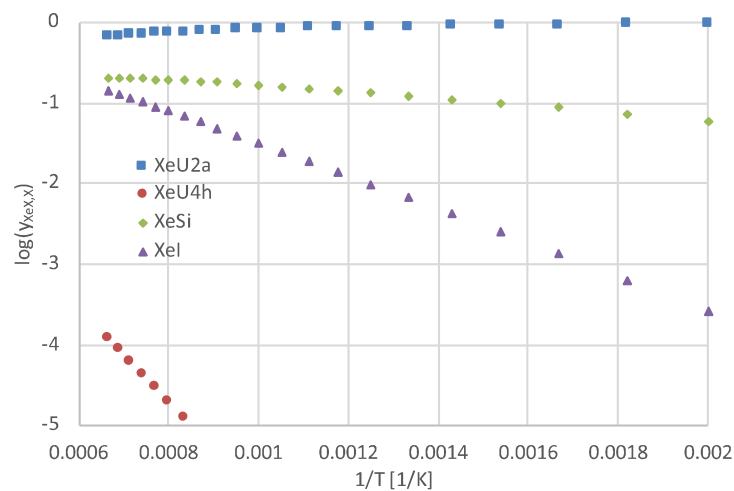

Figure A.3: Fractional occupation of Xe trap sites as function of temperature for $\mathrm{Si}$ and $\mathrm{U}_{-}$-rich conditions in $\mathrm{U}_{3} \mathrm{Si}_{2}$. a) $\mathrm{Si}$-rich and b) U-rich conditions. 


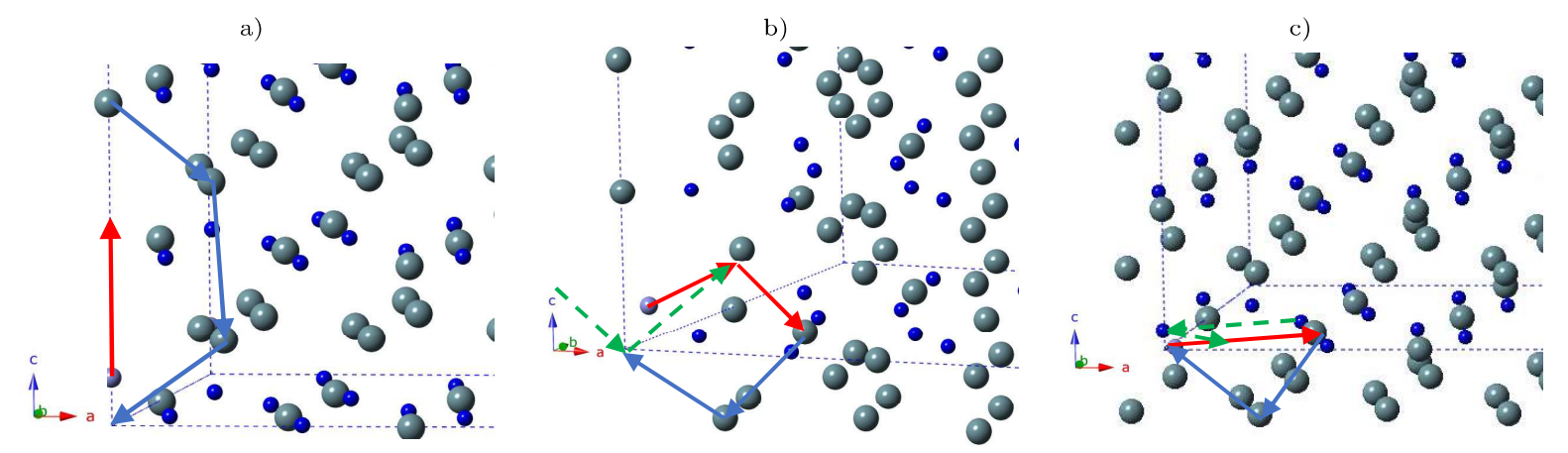

Figure A.4: Diffusion mechanisms for Xe occupying $\mathrm{U} 2 \mathrm{a}$ trap site in $\mathrm{U}_{3} \mathrm{Si}_{2}$. The dotted lines indicate the boundary of the $2 \times 2 \times 3$ computational supercell. For clarity the plots are zoomed in on the mechanism of interest. a) Xe $\mathrm{U}_{2 \mathrm{aU}} \mathrm{a}$ in the $c$ direction (red arrow). The Xe jump is shown, but the rate-limiting step is the intra-cluster move of $V_{U 2 a}$ from its original position to an equivalent site on the other end of the cluster where a second diffusion step can be initiated (blue arrow). b) $\mathrm{Xe}_{\mathrm{U} 2 \mathrm{aU} 4 \mathrm{~h}}$ (or Xe $\mathrm{X}_{4 h U 2 \mathrm{a}}$ ) in the $a-b$ plane. This is also a multi-step mechanism and migration of the Xe atom (red arrows) is not the rate-limiting step, but rather intra-cluster migration of uranium atoms (blue arrows). red The $\mathrm{U} 2 \mathrm{a}$ vacancy must also move to a new location to complete the diffusion step, which occurs by the $\mathrm{U}$ vacancy mechanism in Fig. 4 as notionally indicated by the green dashed arrows. This step has a lower barrier than that corresponding to the blue arrows. c) Xe $\mathrm{U}_{\mathrm{U} 2 \mathrm{Si}}$ (or $\mathrm{Xe}_{\mathrm{SiU} 2 \mathrm{a}}$ ) in the $a-b$ plane. As for the other mechanisms, the initial Xe migration shown by the red arrow is not the rate limiting step, which rather corresponds to moving the $\mathrm{U} 2 \mathrm{a}$ vacancy into a new position through intra-cluster migration (blue arrows). red The Si vacancy must also migrate to a new position according to the green dashed arrows, which occurs by a lower barrier than the step represented by the blue arrows.
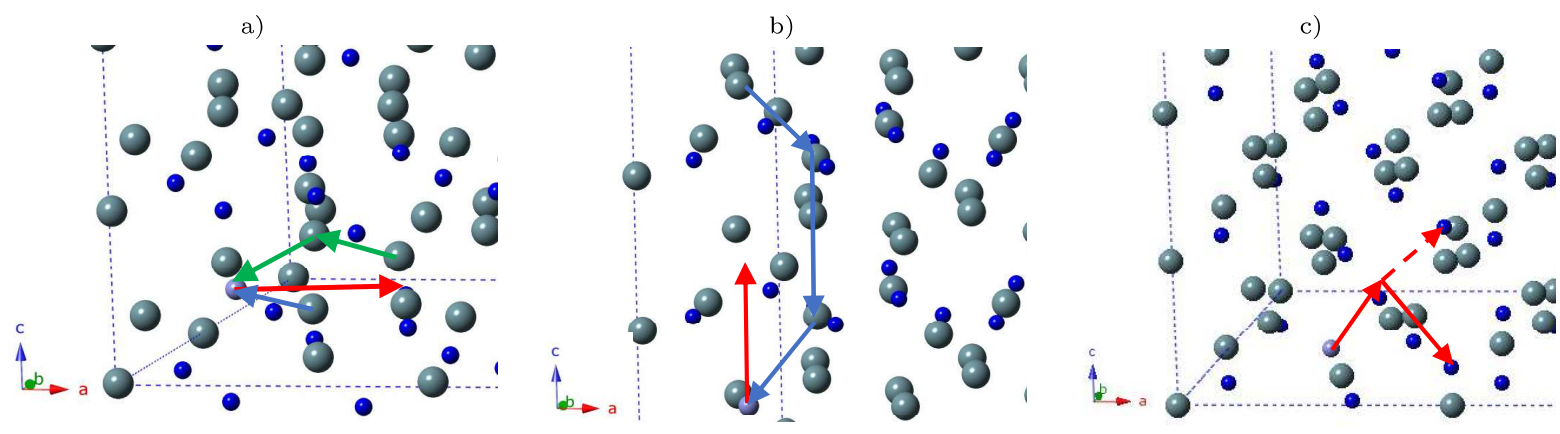

Figure A.5: Diffusion mechanisms for Xe occupying $\mathrm{U}$ 4h trap site in $\mathrm{U}_{3} \mathrm{Si}_{2}$. The dotted lines indicate the boundary of the $2 \times 2 \times 3$ computational supercell. For clarity the plots are zoomed in on the mechanism of interest. a) $\mathrm{Xe}_{U} 4 \mathrm{hU} 4 \mathrm{~h}$ in the $a-b$ plane. The Xe jump is shown by a red arrow. redIn order to complete the diffusion step, the U4h vacancy must migrate from one end of the cluster to the other (blue or green arrows) where a new diffusion step can be initiated. The green arrows offer the most favorable pathway. For this mechanism the Xe jump (red arrows) is the rate-limiting step. b) $\mathrm{Xe}_{\mathrm{U} 4 \mathrm{hU} 4 \mathrm{~h}}$ in the $c$ direction. The Xe jump is illustrated by a red arrow, but as for other cases, the Xe jump to the neighboring vacancy is the rate limiting step (blue redand green arrows). c) $\mathrm{Xe}_{\mathrm{U} 4 \mathrm{hSi}}$ (or $\mathrm{Xe}_{\mathrm{SiU} 4 \mathrm{~h}}$ ) in the $a-b$ plane (solid lines) or in the $c$ direction (dashed line). The $\mathrm{Xe}$ atom is more stable in the Si vacancy, therefore this mechanism is illustrated with that site as the starting point. The Xe step is shown (red arrows). Net diffusion is here assumed to occur by detaching $\mathrm{V}_{\mathrm{Si}}$ or $\mathrm{V}_{\mathrm{U} 2 \mathrm{a}}$ (not shown), of which the former $\left(\mathrm{V}_{\mathrm{Si}}\right)$ constitutes the rate-limiting step. 
a)

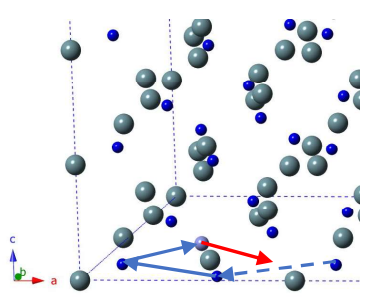

b)

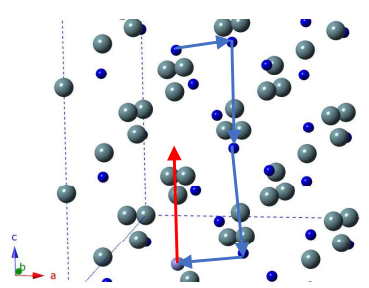

c)

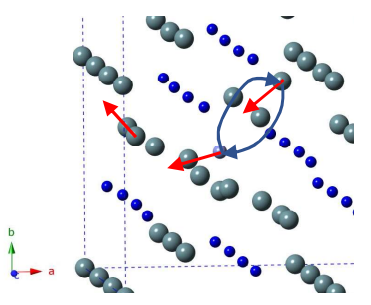

d)

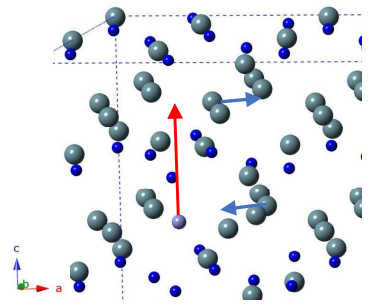

Figure A.6: Diffusion mechanisms for Xe occupying a Si trap site in $\mathrm{U}_{3} \mathrm{Si}_{2}$. The dotted lines indicate the boundary of the $2 \times 2 \times 3$ computational supercell. For clarity the plots are zoomed in on the mechanism of interest. a) XesiSi in the $a-b$ plane. The rate-limiting step is not the $\mathrm{Xe}$ step but rather intra-cluster diffusion of the vacancy. $\mathrm{b}) \mathrm{Xe}_{\mathrm{Si}} \mathrm{V}_{\mathrm{Si}}$ in the $c$ direction. The rate-limiting step is not the $\mathrm{Xe}$ step but rather intra-cluster diffusion of the vacancy. c) $\mathrm{Xe}_{i}$ in the $a$ - $b$ plane. This mechanism involves several steps, including translation (red arrows) which involve a few closely related steps with similar mechanisms and barriers. Rotation (blue arrows) is also required to accomplish long-range diffusion. d) $\mathrm{Xe}_{i}$ in the $c$ direction.

a)

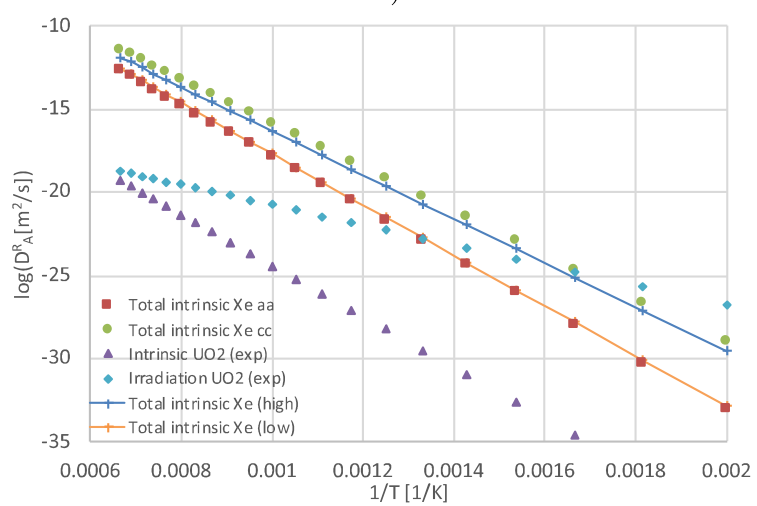

b)

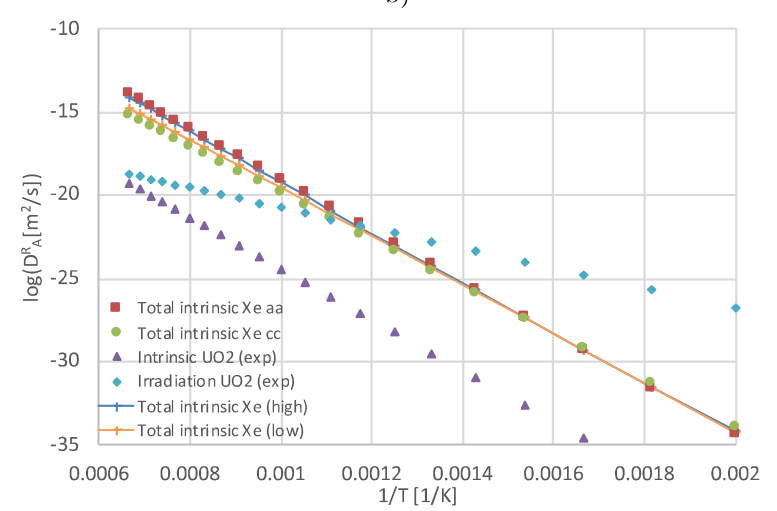

Figure A.7: a) The Xe diffusivity tensor components $\left(D_{\mathrm{Xe}}^{a a}=D_{\mathrm{Xe}}^{b b}\right.$ and $\left.D_{\mathrm{Xe}}^{c c}\right)$ in $\mathrm{U}_{3} \mathrm{Si}_{2}$ under Si-rich thermodynamic conditions. The high and low bounds show the range of possible values in polycrystalline samples. Model predictions based on experimental data for $\mathrm{UO}_{2}$ is also shown as reference [53]. b) The same as in a), but for U-rich thermodynamic conditions. 